\title{
Use of Single Stage Model Rockets to Teach Some Engineering Principles and Practices to First Year Engineering and Engineering Technology Students
}

\section{Dr. Hüseyin Sarper, Old Dominion University}

Hüseyin Sarper, Ph.D., P.E. is a lecturer in Engineering Fundamentals Division at the Old Dominion University in Norfolk, Virginia. He was a professor of engineering and director of the graduate programs at Colorado State University - Pueblo in Pueblo, CO until 2013. He was also an associate director of Colorado's NASA Space Grant Consortium between 2007 and 2013. His degrees, all in industrial engineering, are from the Pennsylvania State University (BS) and Virginia Polytechnic Institute and State University (MS and Ph.D.). His interests include Space, reliability, economic analysis, and renewable energy.

\section{Dr. Linda Vahala, Old Dominion University}

Dr. Vahala received her BS degree from the University of Illinois in 1969, the MS degree from the University of Iowa in 1971, and the Ph.D from Old Dominion University in 1983. Her publications include articles in both plasma physics and atomic physics with an emphasis on laser interactions with plasma and with neutral/rare gas collisions. She has presented her work at various international workshops and meetings, both in Europe and in the United States. She is currently Associate Dean and Director of the Engineering Fundamentals Division. In 1995 , she received the Peninsula Engineer of the Year award. 


\title{
Use of Single Stage Model Rockets to Teach Some Engineering Principles and Practices to First Year Engineering and Engineering Technology Students
}

\begin{abstract}
:
Model rocketry can be considered miniature astronautics. This paper describes a team project using single stage model rockets and solid engines to teach some engineering principles and practices while promoting team work early on. Model rockets were used as an exciting means of accomplishing the main educational goal of introducing students to all stages of engineering problem solving. Model rocketry is a tool that incorporates science, technology, engineering, and mathematics into a challenging activity. How high will/did the rocket go? This is a tough question to answer and the answers are rarely certain. The apogee can be determined using four distinct methods: trigonometry by using a hand held angle measuring tool, use of an onboard altimeter device, simplified analytical calculations based on Newton's second law, and rocket flight simulation. Students received a practical introduction to many engineering concepts they will encounter later on. This paper discusses a major group project using model rockets in a two-hour per week laboratory that is a part of a two-credit course in exploration of engineering and technology at the Old Dominion University in Norfolk, Virginia.
\end{abstract}

\section{Introduction:}

A model rocket is a combined miniature version of real launch and space vehicles. Once a model rocket leaves the launcher, it is a free body in air. Model rockets have been used as projects before. Boyer et al. [1] report a similar project for sophomore aerospace engineering students. Figure 1 shows a cross section of a ready to launch model rocket with a B6-4 solid engine.

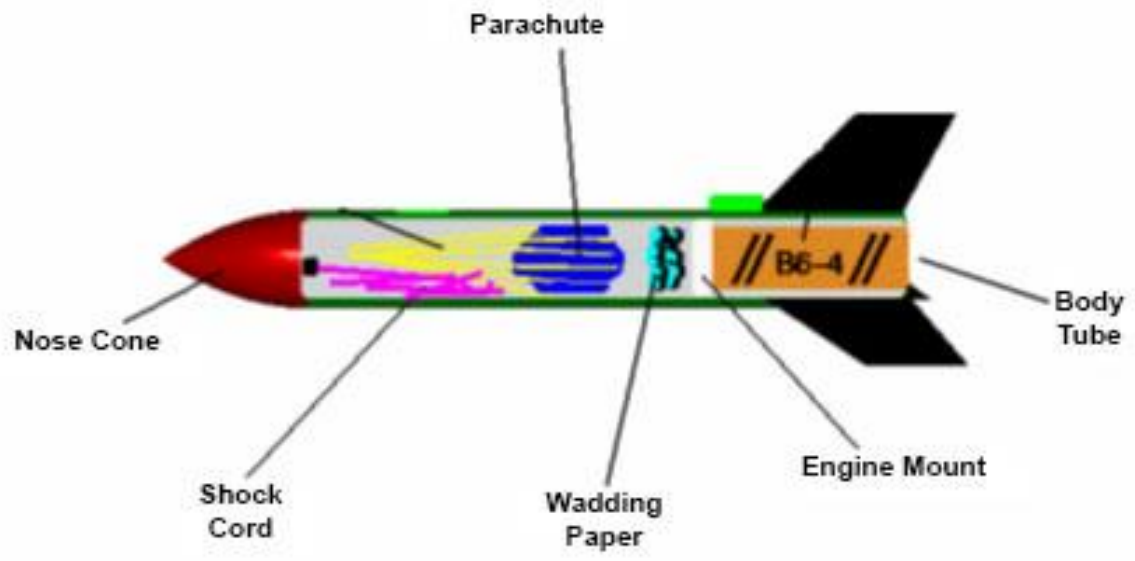

Figure 1. Single stage model rocket with B6-4 engine and other components [1]. 
A model rocket has three flight phases: powered flight, coasting flight, and recovery. Figure 2 shows three phases of a typical flight. The rocket is launched by the ignition of the engine. Model rocket act a lot like the real suborbital rockets.

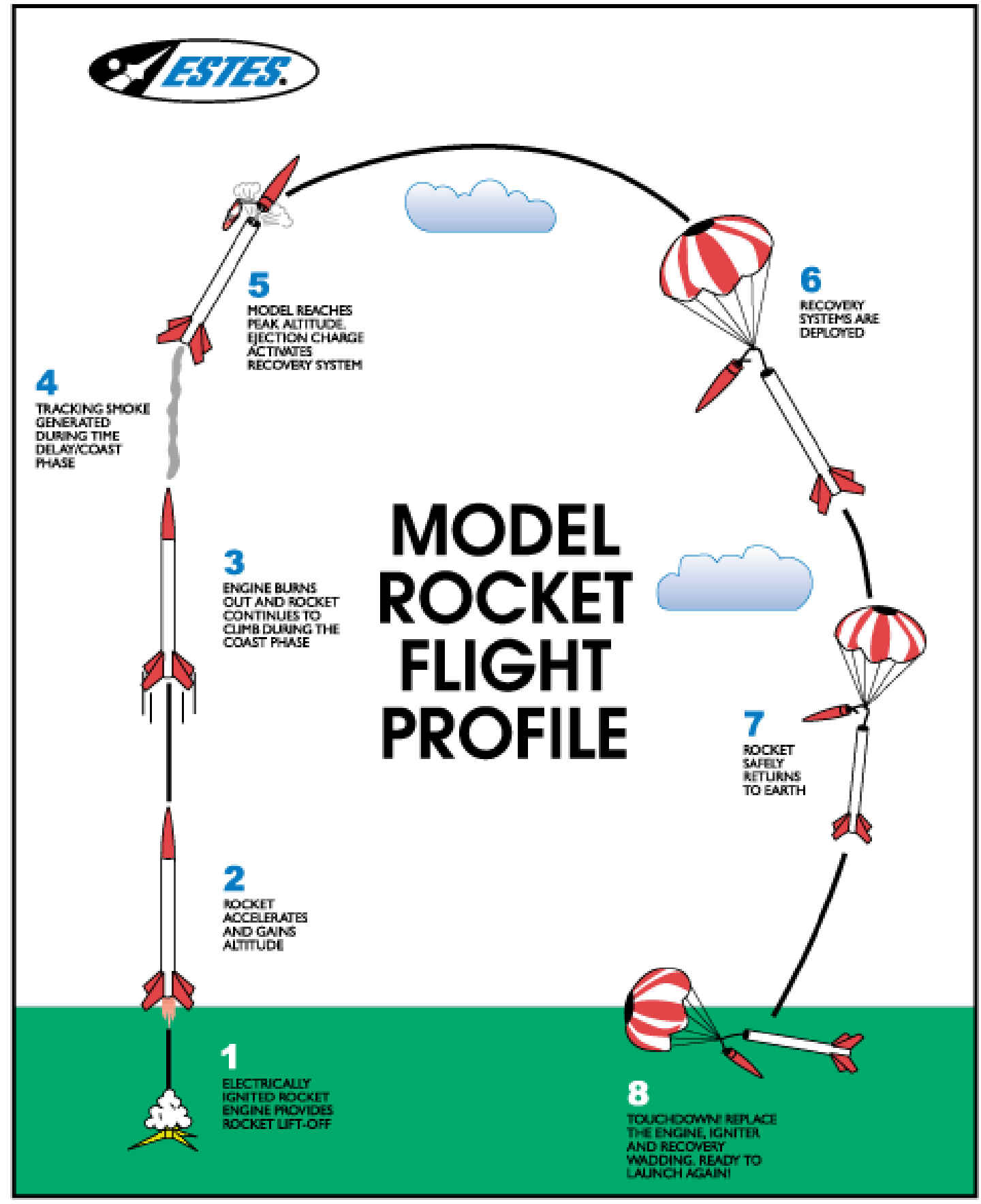

Figure 2. Model rocket flight profile [2].

The engine, shown in Figure 1, is akin to real solid engine. Figure 3 shows the thrust profile for a B4 engine with a maximum and average thrust values of 13.2 and 4 Newtons. Table 1 shows specifications of common solid engines used in introductory model rocket projects. Thrust duration of 1.1 seconds for the B4 engine is shown both in Table 1 and Figure 3. 


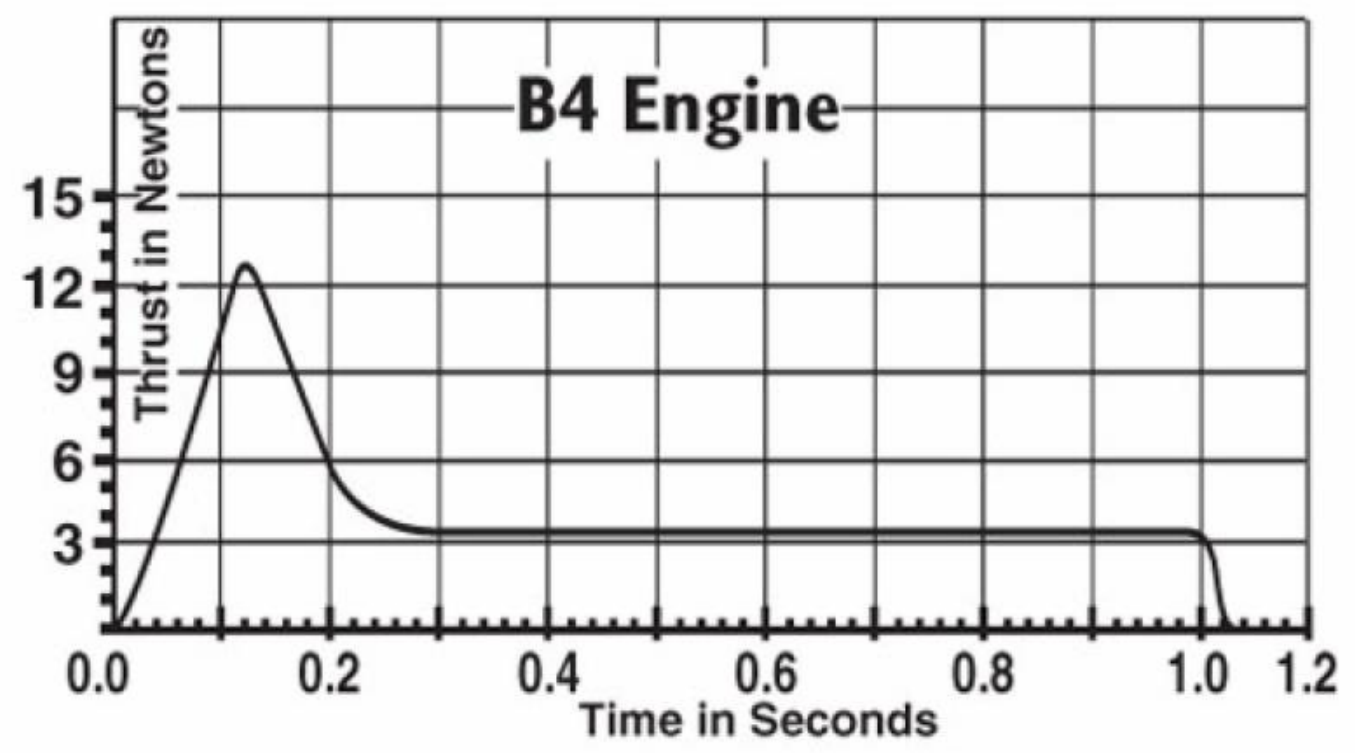

Figure 3. Thrust profile for a sample solid engine [2].

Figure 4 shows a cut-away engine and the flight sequences associated with each engine section. The powered phase of the flight lasts until the engine has consumed all its propellant. During this phase, the model rocket accelerates and moves in response to the forces of thrust, gravity, drag and lift. In order for this phase of flight to be successful, the rocket must be stable. The fins play an important role in achieving stable flight when the rocket is momentarily deflected. When deflected, air moving over the fin travels faster than the air under the fin and lift is created. This lift, generated by relative wind, causes the rocket to rotate so it flies straight again $[2,3]$. 


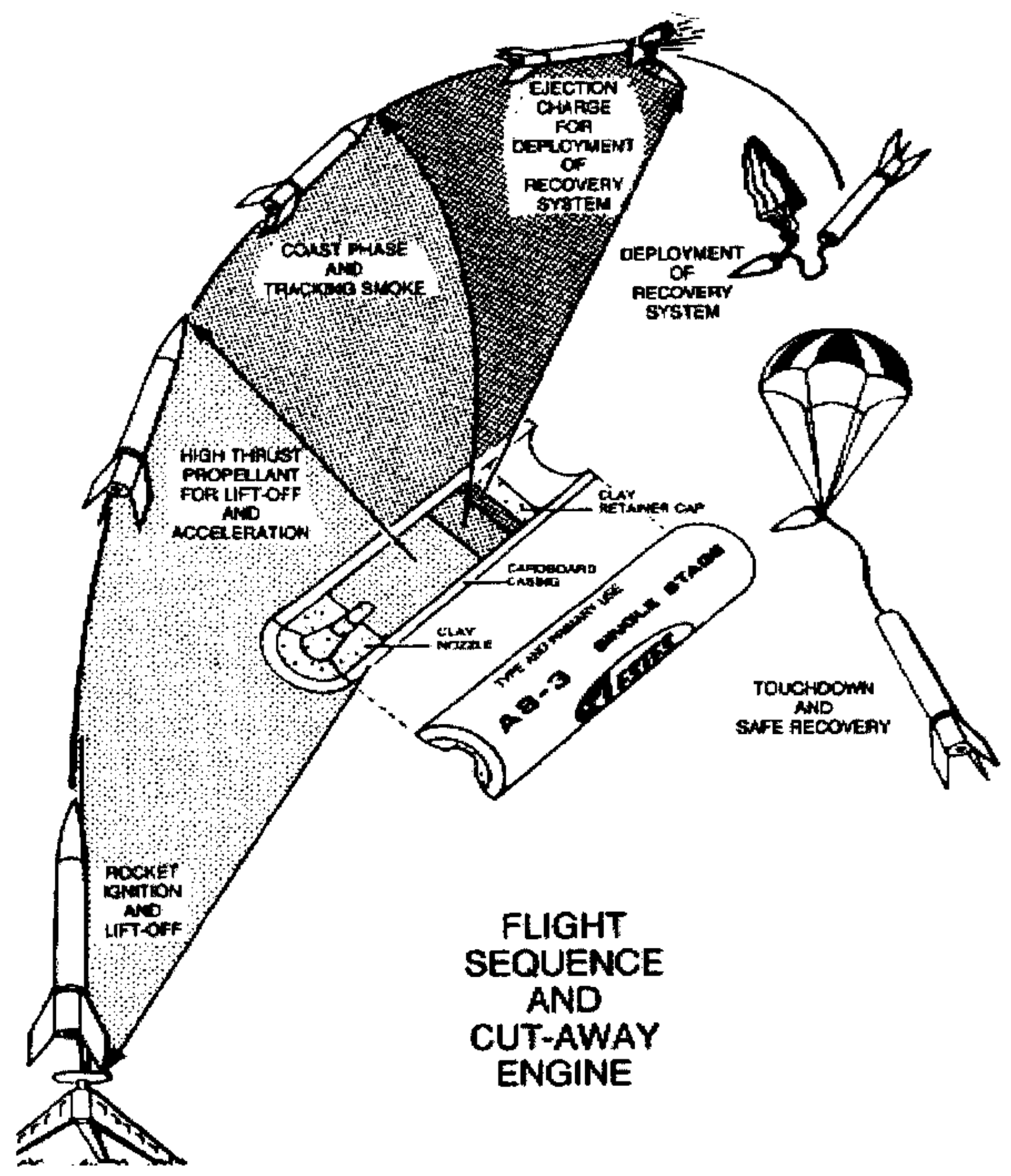

Figure 4. Flight sequence and cut-away engine with matching sections [2]. 
Table 1. Specifications of common solid engines [2]

\begin{tabular}{|c|c|c|c|c|c|c|c|c|c|c|c|c|}
\hline \multirow[t]{2}{*}{$\begin{array}{l}\text { Prod. } \\
\text { No. }\end{array}$} & \multirow[t]{2}{*}{$\begin{array}{l}\text { Engine } \\
\text { Type }\end{array}$} & \multirow{2}{*}{$\begin{array}{c}\begin{array}{c}\text { Total } \\
\text { Impulse }\end{array} \\
\mathrm{N}-\mathrm{sec}\end{array}$} & \multirow{2}{*}{$\begin{array}{c}\begin{array}{c}\text { Time } \\
\text { Delay }\end{array} \\
\text { Sec. }\end{array}$} & \multicolumn{2}{|c|}{$\begin{array}{c}\text { Max } \\
\text { Lift Weight }\end{array}$} & \multicolumn{2}{|c|}{$\begin{array}{l}\text { Max } \\
\text { Thrust }\end{array}$} & \multirow{2}{*}{\begin{tabular}{|c|}
$\begin{array}{c}\text { Thrust } \\
\text { Duration }\end{array}$ \\
Sec.
\end{tabular}} & \multicolumn{2}{|c|}{$\begin{array}{l}\text { Initial } \\
\text { Weight }\end{array}$} & \multicolumn{2}{|c|}{$\begin{array}{c}\text { Propellant } \\
\text { Weight }\end{array}$} \\
\hline & & & & $0 z$. & gm & Newtons & Lbs. & & $0 z$. & $g m$ & 02. & $\mathrm{gm}$ \\
\hline \multicolumn{13}{|c|}{ INGLE STAGE ENGINES (GREEN LABEL) } \\
\hline 1502 & 1/4A3-3T & 0.625 & 3 & 1.0 & 28 & 4.95 & 1.1 & 0.25 & 0.20 & 5.6 & 0.03 & 0.85 \\
\hline 1503 & 1/2A3-2T & 1.25 & 2 & 2.0 & 57 & 8.3 & 1.9 & 0.3 & 0.20 & 5.6 & 0.06 & 1.75 \\
\hline 1507 & $\mathrm{~A} 3-4 \mathrm{~T}$ & 2.50 & 4 & 2.0 & 57 & 8.5 & 1.9 & 0.6 & 0.27 & 7.6 & 0.12 & 3.50 \\
\hline 1511 & $\mathrm{~A} 10-3 \mathrm{~T}$ & 2.50 & 3 & 3.0 & 85 & 13.0 & 2.9 & 0.8 & 0.28 & 7.9 & 0.13 & 3.78 \\
\hline 1598 & A8-3 & 2.50 & 3 & 3.0 & 85 & 11.8 & 2.7 & 0.5 & 0.57 & 16.2 & 0.11 & 3.12 \\
\hline 1601 & $B 4-2$ & 5.00 & 2 & 4.0 & 113 & 13.2 & 3.0 & 1.1 & 0.70 & 19.8 & 0.29 & 8.33 \\
\hline 1602 & B4-4 & 5.00 & 4 & 3.5 & 99 & 13.2 & 3.0 & 1.1 & 0.74 & 21.0 & 0.29 & 8.33 \\
\hline 1605 & B6-2 & 5.00 & 2 & 4.5 & 127 & \begin{tabular}{|l|}
12.1 \\
\end{tabular} & 2.7 & 0.8 & 0.68 & 19.3 & 0.22 & 6.24 \\
\hline 1606 & B6-4 & 5.00 & 4 & 4.0 & 113 & \begin{tabular}{|l|}
12.1 \\
\end{tabular} & 2.7 & 0.8 & 0.71 & 20.1 & 0.22 & 6.24 \\
\hline 1617 & C5.3 & 10.00 & 3 & 8.0 & 226 & 21.0 & 4.7 & 1.9 & 0.90 & 25.5 & 0.45 & 12.70 \\
\hline 1613 & $\mathrm{C} 6.3$ & 10.00 & 3 & 4.0 & 113 & 15.3 & 3.4 & 1.6 & 0.88 & 24.9 & 0.44 & 12.48 \\
\hline 1614 & $\mathrm{C} 6.5$ & 10.00 & 5 & 4.0 & 113 & 15.3 & 3.4 & 1.6 & 0.91 & 25.8 & 0.44 & 12.48 \\
\hline 1666 & D12-3 & 20.00 & 3 & 14.0 & 396 & 32.9 & 7.4 & 1.6 & 1.49 & 42.2 & 0.88 & 24.93 \\
\hline 1667 & D12-5 & 20.00 & 5 & 10.0 & 283 & 32.9 & 7.4 & 1.6 & 1.52 & 43.1 & 0.88 & 24.93 \\
\hline \multicolumn{13}{|c|}{ UPPER STAGE ENGINES (PURPLE LABEL) } \\
\hline 1504 & $1 / 2 \mathrm{~A} 3-4 \mathrm{~T}$ & 1.25 & 4 & 1.0 & 28 & 8.3 & 1.9 & 0.3 & 0.21 & 6.0 & 0.06 & 1.75 \\
\hline 1607 & B6-6 & 5.00 & 6 & 2.5 & 71 & 12.1 & 2.7 & 0.8 & 0.78 & 22.1 & 0.22 & 6.24 \\
\hline 1615 & C.6.7 & 10.00 & 7 & 2.5 & 71 & 15.3 & 3.4 & 1.6 & 0.95 & 26.9 & 0.44 & 12.48 \\
\hline \multicolumn{13}{|c|}{ BOOSTER STAGE ENGINES (RED LABEL) } \\
\hline 1616 & $\mathrm{C} 6=0$ & 10.00 & None & 4.0 & 113 & 15.3 & 3.4 & 1.6 & 0.80 & 22.7 & 0.44 & 12.48 \\
\hline 1665 & D12.0 & 20.00 & None & 14.0 & 396 & 32.9 & 7.4 & 1.6 & 1.44 & 40.9 & 0.88 & 24.93 \\
\hline
\end{tabular}

A stable rocket always flies into the relative air flow. Any wind blowing across the launch field affects the flight path of a model rocket. The aerodynamic force of drag is very important. The formula $[2,3]$ for drag force is as follows:

$$
D=0.5 p V^{2} C_{d} A
$$

where $(p)$ is the density of the air. $C_{d}$ is the coefficient of drag that depends on the shape and smoothness of the rocket. $\mathrm{V}$ is the velocity and $\mathrm{A}$ is the frontal area. A high thrust engine will cause a rocket to experience more drag than a low thrust engine due to higher velocity.

However, higher thrust engine still results in a higher apogee. Coasting phase begins when the propellant is totally consumed at the burn out point. The delay element is ignited and it burns for the length of time shown in Table 1 above. The delay element controls the deployment of the recovery system. Recovery system (parachute) deployment occurs at apogee or on the way down right after reaching the apogee. During the coasting phase, the rocket slows down since the engine no longer produces thrust. The smoke that is observed comes from the smoke-tracking and delay element of the engine. Recovery phase starts as soon as the smoke-tracking and delay element is exhausted $[2,3]$. If the parachute does not deploy, the model rocket becomes a "missile" that can be dangerous. Very small model rockets do not need a parachute if they are not expected to go very high. 


\section{Model Rocket Safety:}

Model rockets can be dangerous if not handled safely. The appendix contains model rocketry safety code. Each student turns in a homework early in the semester by handwriting the entire code shown in the appendix. Students are also asked to find and report a model rocket accident in the same homework.

\section{Model Rocket Procurement:}

Model rockets are available in two common forms: ready to fly (RTF) and to be constructed from a kit (CFK). The RTF models look nicer and are more expensive and easier to use. Figure 5 below shows the RTF models used for demonstration and estimation of drag effect factor "d" in equation 10. The RTF model rockets in Figure 5, from left to right, are Fat Jack, Rattler-7, MaxTrax, and Skytrax. While some models can be fitted with a payload space using additional attachments, Skytrax RTF model comes with its own payload space. A payload can be an altimeter as in Figure 5 or anything else that is allowable including an egg or an insect.

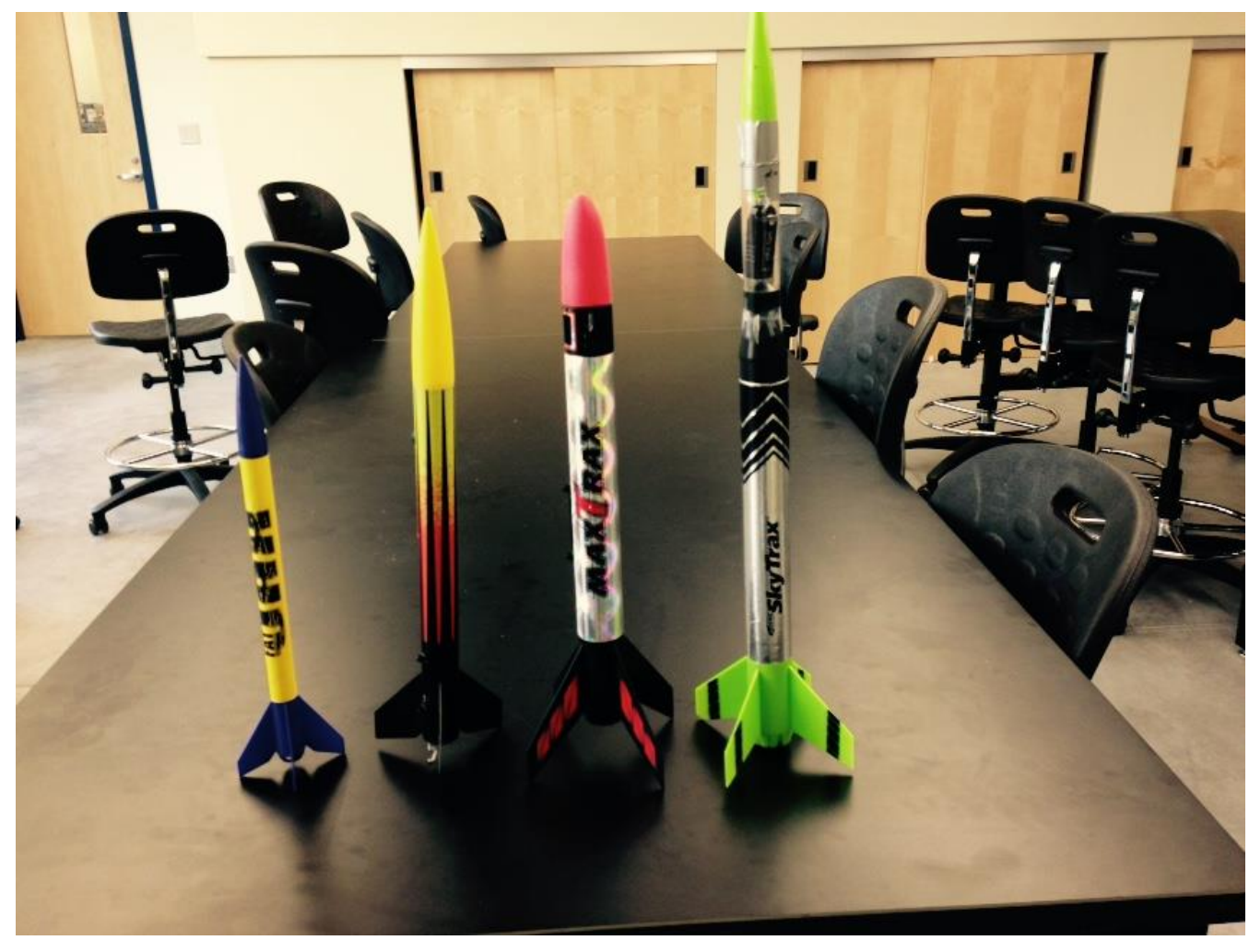

Figure 5. RTF model rockets used for practice and drag effect estimation.

Figure 6 shows the lift-off of Skytrax RTF model rocket which was the favorite model of the majority of the 110 students in four Fall 2014 laboratory sections. Figure A.1 in appendix shows ascend pictures of this model. Pictures were taken by a camera placed under the launch pad. 


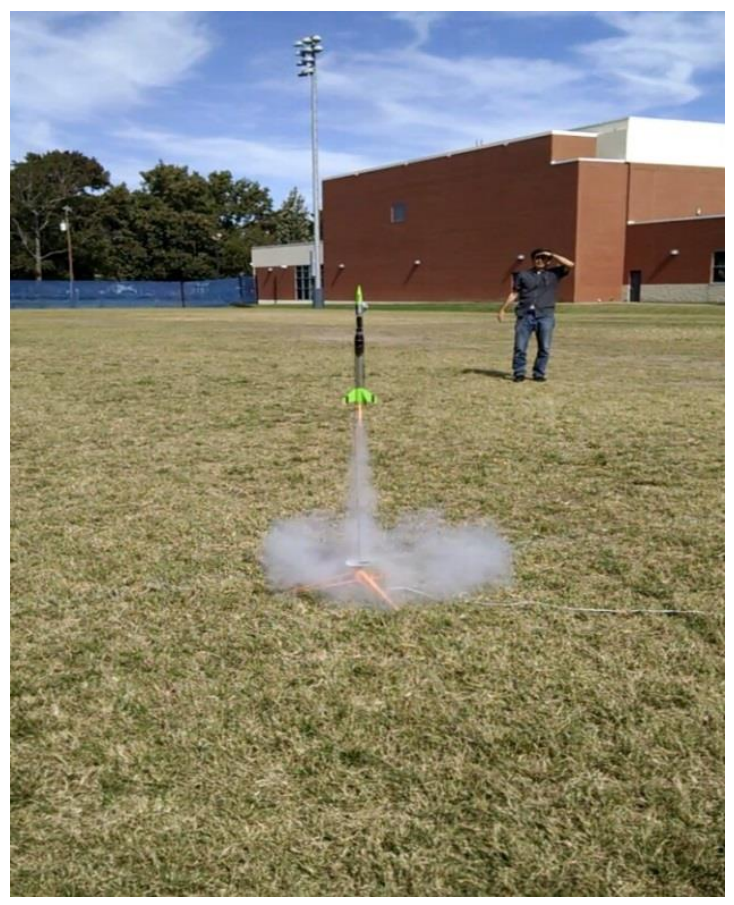

Figure 6. RTF model rocket Skytrax clears the launch pad (Fall 2014).

Student teams used CFK type models for their team project. The model chosen for Fall 2014 team projects was Avion shown in Figure 7 below. A much larger CFK model (Quest Big Dog, shown in Figure 12) is being used for Spring 2015 projects.

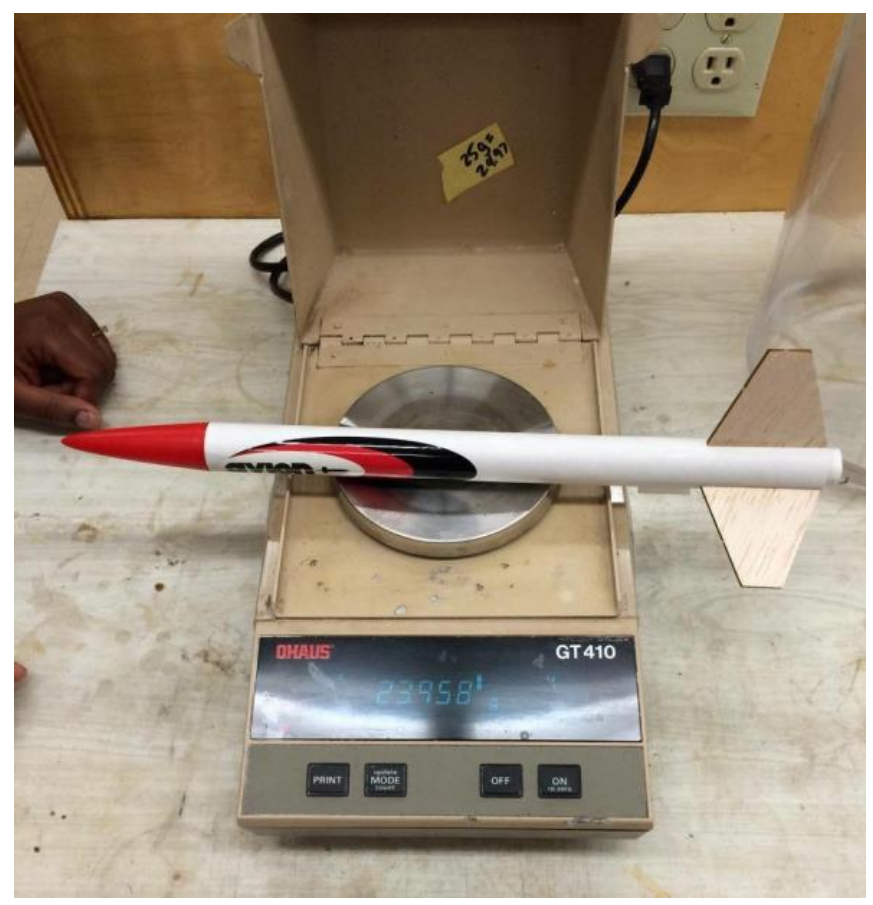

Figure 7. CFK model Avion rocket used by all 29 project teams in Fall 2014. 
Figure 8 shows student teams constructing the model rocket Avion. Each team of randomly chosen three to four students elected a manager who coordinated the project work including writing of the report.

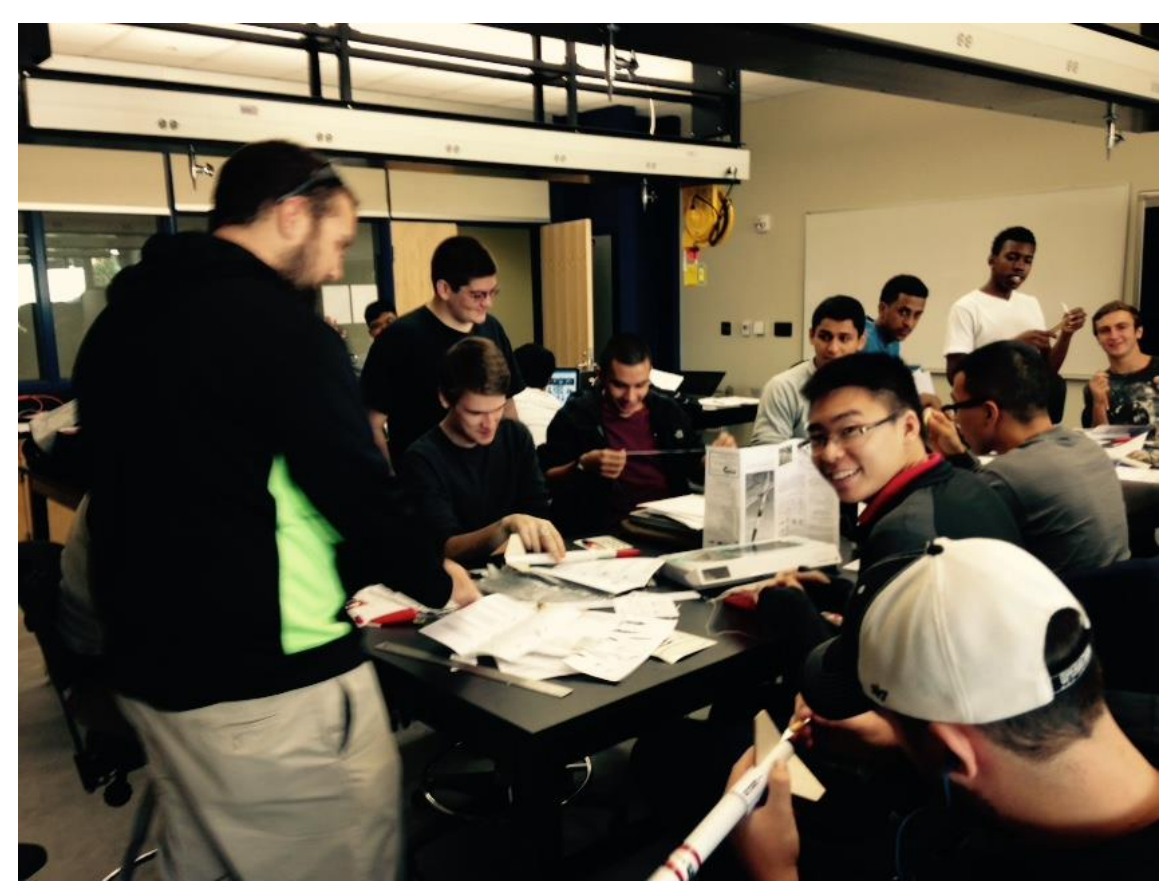

Figure 8 . Teams of students in model rocket construction activity.

Figure 9 shows some of the finished Avion model CFK rockets.

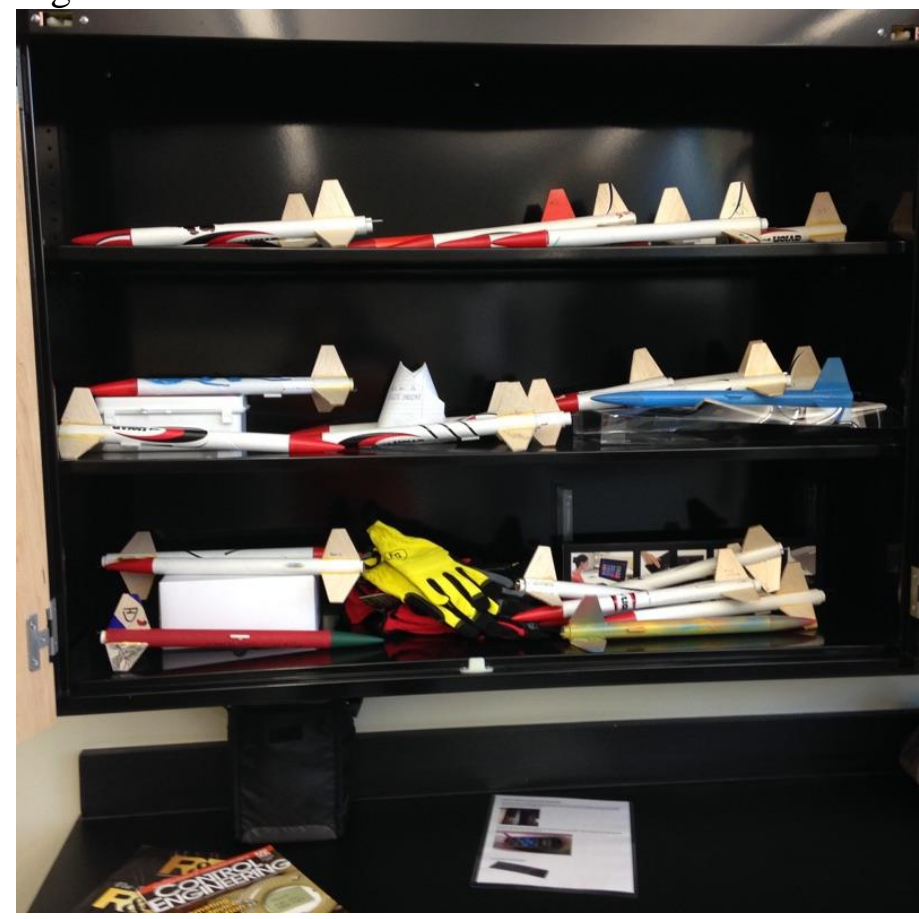

Figure 9. A fleet of completed Avion CFK model rockets. 
Figure 10 shows pre-launch activities of Avion model CFK rockets. Figure 11 shows the Avion on its way up.

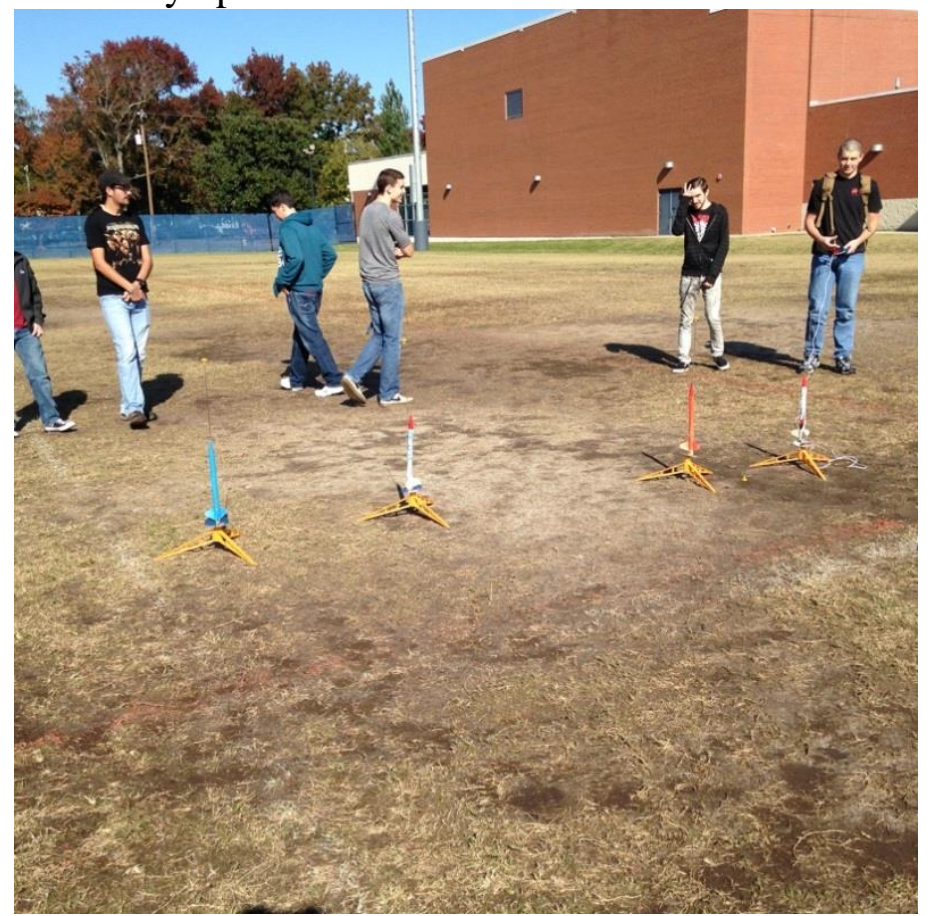

Figure 10. Pre-launch activities.

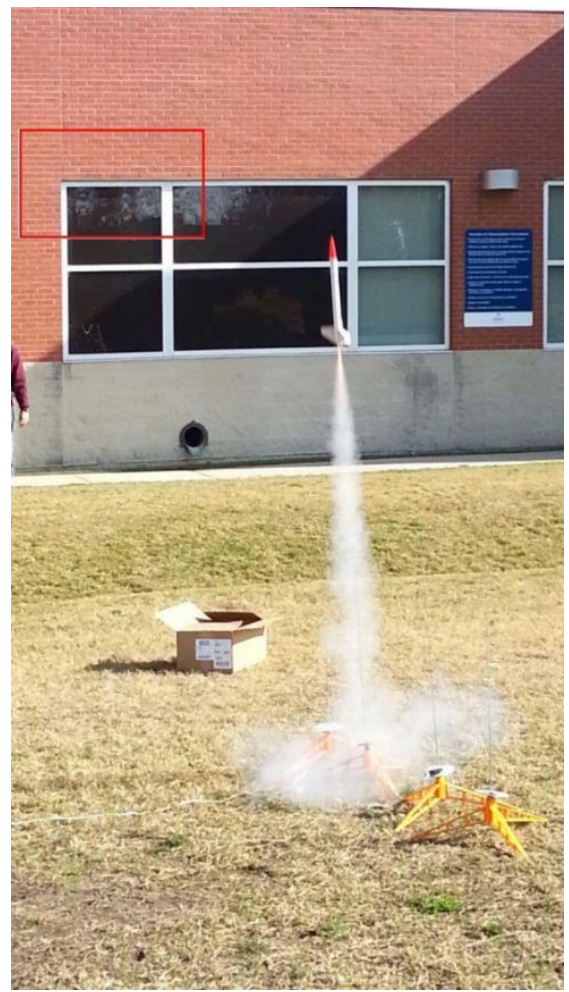

Figure 11. Avion CFK model rocket clears the launch pad.

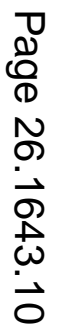




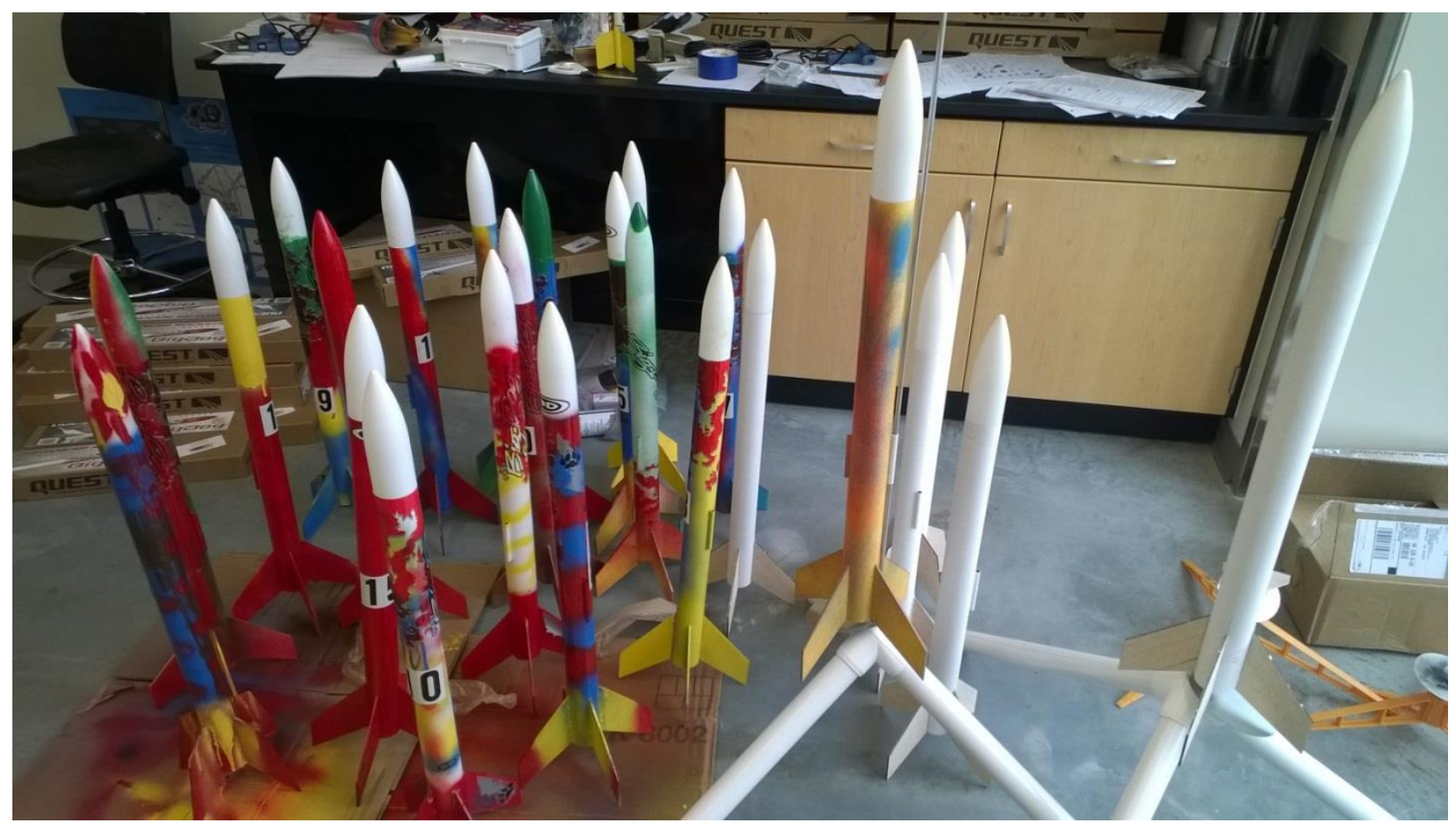

Figure 12. QUEST Big Dog CFK model rockets used for spring 2015 team projects

\section{Methods of Calculating the Apogee for Single Stage Model Rockets}

Four methods were studied. Each method has its own advantages and disadvantages. Freshmen working in teams gained an understanding that they need to try various methods to find alternate solutions and that different methods result in different answers. Each method is subject to error to due to assumptions and uncontrollable external factors.

Method 1 - Analytical Solution Using Newton's Second Law: If we assume it is a vertical flight with zero degree of angle of attack and ignore the lift as a force to simplify calculations, there are three force factors on a model rocket as shown in Figure 13 below.

1) Thrust ( $\mathrm{T}$ ) from the engine acts on the back of the model and makes it accelerate,

2) Gravity (W) is the force that slows the model in its vertical flight. This force decreases slightly over time due to propellant consumption,

3) Aerodynamic drag (D) force that also acts to slow down the model. 


\section{UPWARD MOTION}

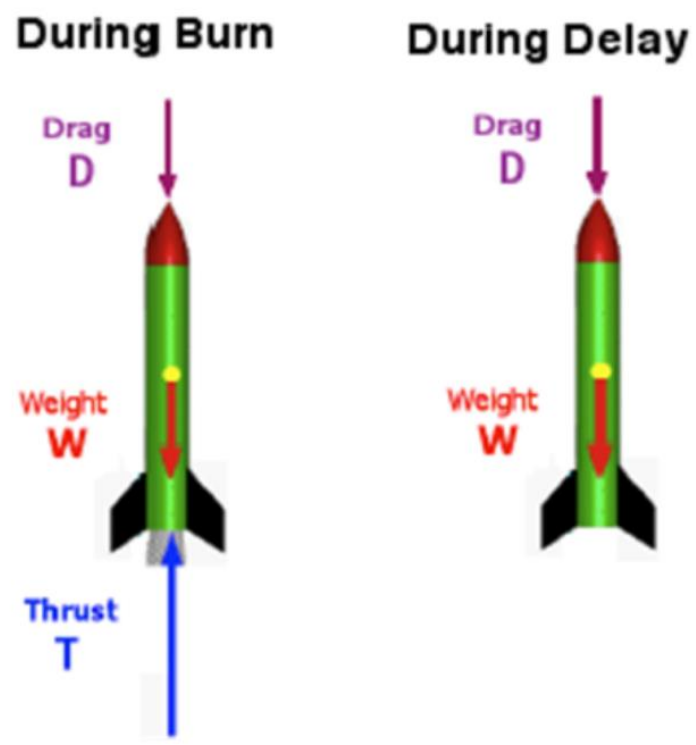

Figure 13. Simplified free body diagram of a model in vertical fight [6]

During powered flight, all three forces acts upon the model. But during coasting flight on the right, thrust is zero. Freshmen are introduced to Newton's three laws of motion although some were exposed to them in high school physics.

1. Objects at rest will stay at rest, and objects in motion will stay in motion in a straight line at constant velocity unless acted upon by an unbalanced force,

2. Force is equal to mass times acceleration. $F=m$ a (2). This equation applies to launching the rocket off the launch pad. Thrust is a forward propulsive force that moves an object and is produced by the engine. As the engine ignites and thrust develops, the forces become unbalanced. The rocket then accelerates. Rocket propellant is burned and converted into gas that expands and then escapes from the rocket. Acceleration is the rate at which the gas escapes. The gas inside the engine picks up speed as it leaves the engine.

3. For every action there is always an opposite and equal reaction. A model rocket will lift off if it expels gas out of its engine. The rocket pushes on the gas and the gas pushes on the rocket [2]. The action, then, is the expulsion of gas out of the engine. In return, the reaction is the departure of the rocket skyward.

Most of the students seemed to like this discussion especially after the first practice launches. F in equation 2 is the sum of all applied forces in Figure 13, $\mathrm{m}$ is the mass of the model including the engine and $a$ is the resulting acceleration. 
To calculate the apogee of a single stage model rocket, Impulse, $I_{t}=m_{1} v_{1}-m_{0} v_{0}$ (3) where, $m_{1}=$ mass at burnout, $v_{1}=$ velocity at burnout, $m_{0}=$ mass at lift-off, $\quad v_{0}=$ velocity at lift-off which is zero. Impulse is also force $\mathrm{x}$ time. Thrust $=$ total impulse/burn time. Using equation 2, the net force ignoring the drag is $\mathrm{T}-\mathrm{W}=\mathrm{m}$ a. Then, $\mathrm{T}-\mathrm{W}=(\mathrm{W} / \mathrm{g})\left(V_{\max } / \mathrm{t}\right)$ (4) where $V_{\max }=\mathrm{at}$ and $\mathrm{m}=(\mathrm{W} / \mathrm{g})$. Then, $V_{\max }=[(\mathrm{T} / \mathrm{W})-1] \mathrm{g} \mathrm{t}$

The term $V_{\max }$ is the velocity at the end of the thrust period and called burnout velocity. It is also the maximum velocity the model can attain. At lift-off, the propellant to total rocket mass ratio is about $5 \%$ for most model rocket and engine combinations. This ratio is much higher with real rockets. This issue is discussed in the lab by looking up some real rocket ratios on the web. The ratio of the propellant's weight to the model rocket's weight is very small. As the flight the mass stays fairly constant and the force is fixed, acceleration can be assumed constant. The velocity is acceleration times the thrust time $(\mathrm{V}=\mathrm{at})$ where, $\mathrm{t}$ is the end of the thrust duration. The average velocity during thrusting is the average of initial and maximum velocities or just half of the maximum velocity: $\mathrm{V}_{\mathrm{av}}=V_{\text {max }} / 2(\mathbf{6})$.

While thrusting for $\mathrm{t}$ seconds, the model rocket will climb a distance of $\mathrm{S}_{\mathrm{b}}=\mathrm{v} \mathrm{t}=\mathrm{V}_{\mathrm{av}} \mathrm{t}$

When the engine stops thrusting, the model rocket starts its coasting flight and climbs up an additional distance of $\mathrm{S}_{\mathrm{c}}=\left(V_{\max }\right)^{2} / 2 \mathrm{~g}$ (8). The apogee is the sum of both distances, $S_{t}=S_{b}+S_{c}$

This analysis neglects lift and drag forces, but this was necessary to keep the project calculations as simple as possible while still maintaining some engineering rigor. The aerodynamic drag has a big effect on the actual altitude. Stine's text [3] states that aerodynamic drag lowers the computed drag-free maximum altitude of a model rocket by 50 percent (for low-powered models) to as much as 80 percent (for high-powered models). Then, the actual apogee is: $S=S_{t} * d$

Equation 10 was used in this project, but value of coefficient " $\mathrm{d}$ " is never found in engine specification of any manufacturer. As a part of the overall model rocketry exercise, experiments were conducted to calculate the value of this coefficient so that calculations in team reports can be more reliable. The results of this effort are reported in the next section.

Method 2 - Use of an Altimeter: It is possible to purchase an altimeter device and add it as payload to a model rocket, but not all models have a payload space. Figure 14 shows "altimeterone" brand device used for instruction and demonstration in Fall 2014. This altimeter was hooked to the nose cone of Skytrax RTF model and inserted into the available payload tube. No altimeter was used with team project model rocket Avion because there was no payload space. The altimeter weighs about 10 grams and costs around $\$ 60$. In addition, almost a third of the team project model rockets were lost due to wind and limited campus launch space availability. 


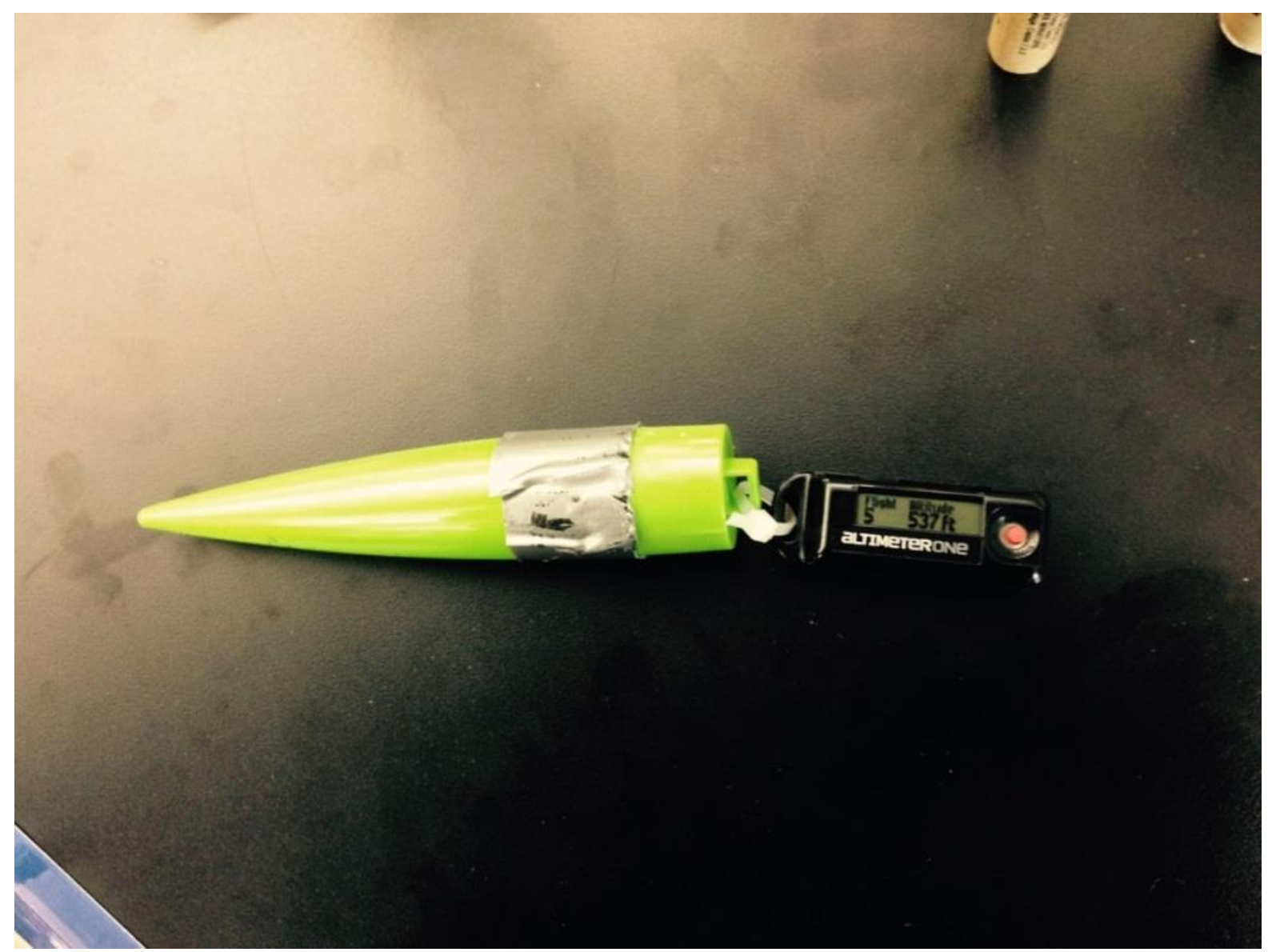

Figure 14. Altimeter as a payload onboard a Skytrax RTF model for Method 2.

Method 3 - Use of Trigonometry : To find the actual apogee the model rocket reaches, it is possible to use ESTES AltiTrak device shown in Figure 15.

To ensure accuracy the observer must be located at some distance (100 to 500 feet) from the rocket launch site and kneel down or stay as low as possible. Once the observer is at the correct distance (Figure 16), he/she holds the altitude finder at arm's length, pointed at the rocket and pull the trigger and waits for the launch [2]. When the rocket lifts off, the observer follows it through the sights on the finder. As the rocket reaches the maximum altitude, trigger is released. The observer reads the degrees on the side of the finder and records it. Equation 11 calculates the apogee. About three feet must be added if the observer is not in a level near zero position to match the initial position of the model rocket.

Altitude $=[$ Distance $* \tan (\alpha)]+3$ 


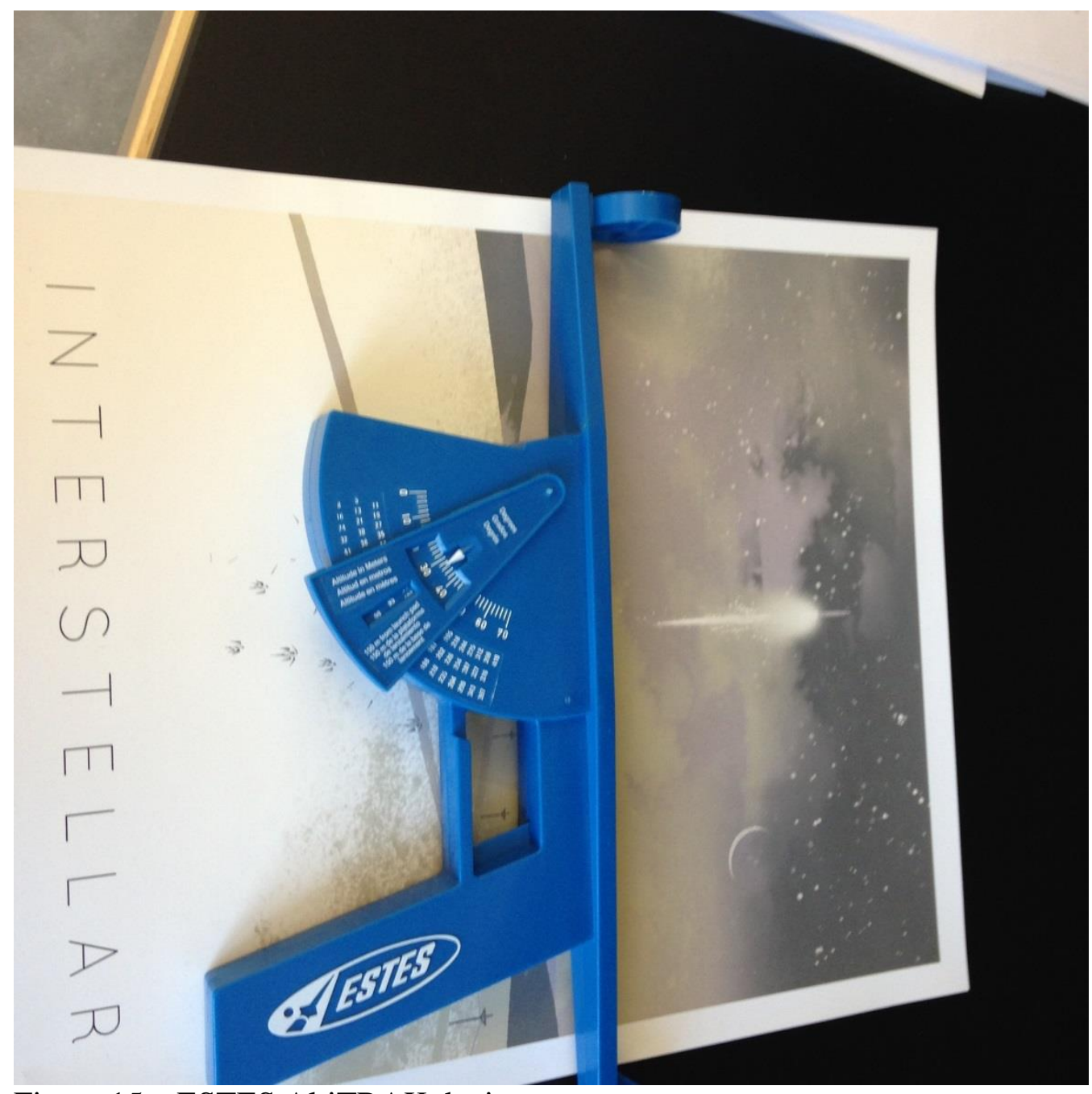

Figure 15. ESTES AltiTRAK device.

This method works well with low flying models in very calm weather conditions. The device is limited to 70 degrees and long observation distance is required for even mid-power engines. Three or four devices were used in different directions from the launch pad to calculate average angle. Not surprisingly, each observer reported a different angle albeit being close enough in most cases.

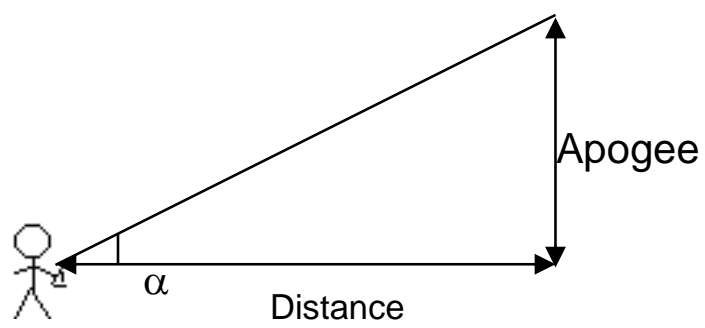

Figure 16. Finding altitude using trigonometry 
Method - 4: Simulation: Dynamic simulation of model rockets can be done using several software packages. Rocksim [5] software was purchased for this purpose. Avion and Big Dog CFK model rocket simulation files are already available in the tutorial section of this software. Avion simulation results using A8-3 and B6-4 engines are in the appendix. The initial plan included using the software in lab instruction, but this was not accomplished because it is difficult to teach software with many confusing input requirements. However, students were able to run simulation and see animated flight profiles.

\section{Estimation of Coefficient "d" in Equation 10:}

It would be very convenient if coefficient " $\mathrm{d}$ " were available for each model rocket and engine combination, but this is clearly not possible. Stine's text [3] provides a range of 0.2 to 0.5 . As a part of many practice launches, there were three cases for which credible apogee data were available. The shipping box of Estes Corporation's RTF model "Fat Jack" lists apogee as 425 feet using an A3-4T engine. Method 1 calculation results in 1160.6 feet before the drag effect. This suggests $d=0.366$. Method 1 results in 393.17 feet before drag for RTF model Skytrax with a B4-4 engine. The shipping box lists apogee as 275 feet using B4-4 engine. Here, $d$ is found as 0.7 . The value of 0.7 seems too high, but it was kept anyway. Finally, an altimeter was flown on RTF model Skytrax several times using a C6-5 engine. The average observed apogee was 423.5 feet. Model 1 results in an apogee of 1288 feet before the drag effect and d is found as 0.33. It would have been nice to simulate these engine combinations using Skytrax RTF model for additional information, but that was not possible. It was decided to average these three empirical d values and use the average (0.47) in team report calculations. Students were part of this discussion throughout the semester. They learned that many problems do not come with complete data and engineers need to improvise in a justifiable manner.

\section{Sample Team Report Calculations:}

Results from two team reports are reproduced below using two engine types: A8-3 and B6-4. There were 29 student teams in Fall 2014 (22 teams in Spring 2015) and some teams were able to use both engine types if the model rocket was not lost due to wind and not damaged after the first launch.

\section{AVION FLIGHT 14 :}

Rocket: Avion $\quad$ Engine: A8-3. The model weight: $25.1 \mathrm{~g}$. Total Weight Including the Engine:

$$
\begin{aligned}
& W_{o}=(\text { Rocket weight })+(\text { engine weight }) \quad W_{o}=25.106 g+16.79 g \\
& =41.896 \mathrm{~g}
\end{aligned}
$$

Propellant Weight for A8-3 Engine $\quad W_{p}=3.12 \mathrm{~g}$ Impulse for A8-3 Engine $\quad I=2.5 \mathrm{~N}-\mathrm{sec}$ Thrust Duration for A8-3 Engine: $\Delta t=0.5 \mathrm{sec}$ Initial Velocity: 0 . Calculated Information:

1. Average Weight to Burnout Calculation

$$
W_{b}=W_{o}-\frac{W_{p}}{2} \quad W_{b}=41.896 g-\frac{3.12 g}{2}=40.336 g \quad W_{b}=\frac{40.336}{454.5}=0.08875 \mathrm{lbs} .
$$


2. Thrust Calculation

$$
T=\frac{I}{\Delta t} \quad T=\frac{2.5}{0.5}=5 \mathrm{~N} \quad T=5 * 0.2248=1.124 \mathrm{lbs} .
$$

3. Velocity at Burnout or Maximum Velocity Calculation

$$
T=\left(\frac{T}{W_{b}}-1\right) g * \Delta t \quad T=\left(\frac{1.124}{0.08875}-1\right)(32.2)(0.5)=187.803 \mathrm{ft} / \mathrm{sec}
$$

4. Velocity at Burnout in Miles Per Hour (just for reference)

$$
W_{b}=(187.803)\left(\frac{3600}{5280}\right)=128.05 M P H
$$

5. Average Speed To Burnout Calculation

$$
V_{a v}=\frac{V_{o}+V_{b}}{2} \quad V_{a v}=\frac{0+187.803}{2}=93.90 \mathrm{ft} / \mathrm{sec}
$$

6. Altitude at Which Burnout Occurs (fuel is used up and rocket reaches maximum speed)

$$
S_{b}=V_{a v} * \Delta t \quad S_{b}=(93.90)(0.5)=46.95 \mathrm{ft}
$$

7. Coasting Distance Calculation

$$
S_{c}=\frac{V_{b}^{2}}{2 g} \quad S_{c}=\frac{(187.803)^{2}}{2(32.2)}=547.67 \mathrm{ft}
$$

8. Total Altitude Without Air Drag Calculation

$$
S_{t}=S_{b}+S_{c} \quad S_{t}=46.95+547.67=594.62
$$

9. Actual Altitude or Apogee Calculation

$$
S_{q}=S_{t} * d \quad S_{q}=(594.62)(0.47)=279.50 \mathrm{ft}
$$

10. Comments and Comparison to Triangulation Method Result

Angles taken from 200 feet away from launch site are 54, 55, 49.5.

Average: $\alpha=52.8$ degrees.

Apogee: $h=\tan (52.8)(200)+3=266.50$ feet 
Conclusion: Two methods provide fairly close apogee values. Simulation method results in a value of 300.75 feet. It is highly likely that the true apogee is near the average ( 282.25 feet) of these three methods $(279.50,266.50$, and 300.75$)$ for this rocket/engine combination. No altimeter can be loaded on this model. The average observed time to the apogee was 4.73 seconds. 3.5 seconds is due to thrust (0.5) duration and ejection delay (3). The rocket was observed to be still climbing briefly before beginning its descend, but after the ejection charge. It is reasonable to assume that the remaining time ( 1.23 seconds) was due to that brief observation. There were 19 other team launches using A8-3 engine. Not all results were as close as the ones reported from this student team report.

\section{AVION FLIGHT 25:}

Rocket: Avion Engine: B6-4 The model weight: $28.46 \mathrm{~g}$ (heavier than most due to optional spray paint used). Total weight including engine $\left(\mathrm{W}_{\mathrm{o}}\right)=46.75$ grams , propellant weight $\left(\mathrm{W}_{\mathrm{p}}\right)=$ 6.24 grams Impulse $(\mathrm{I})=5.00 \mathrm{~N}-\mathrm{s}$, Thrust Duration $(\Delta \mathrm{t})=0.8 \mathrm{sec}$.

1. Average Weight to Burnout $\left(\mathrm{W}_{\mathrm{b}}\right)$

a. $W_{b}=W_{o}-\frac{W_{p}}{2}=46.75-\frac{6.24}{2}=43.63$ grams

b. Converted to Pounds: $43.63 / 454.5=.096$ pounds

2. $\operatorname{Thrust}(\mathrm{T})$

a. $\mathrm{T}=\mathrm{I} / \Delta \mathrm{t}=5 / .8=6.25$ Newtons

b. Convert to Pounds: $6.25 * 0.2248=1.405$ pounds

3. Velocity at Burnout
a. $V_{b}=\left(\frac{T}{W_{b}}-1\right) g * \Delta t$
b. $V_{b}=\left(\frac{1.405}{.096}-1\right) 32.2 *(.8)=351.24 \mathrm{ft} / \mathrm{sec}$

4. In MPH: $351.24 * 3600 / 5280=239.48 \mathrm{MPH}$

5. Average Speed to Burnout

$$
V_{A v}=\frac{V_{o}+V_{b}}{2}=\frac{0+351.24}{2}=175.62 \mathrm{ft} / \mathrm{sec}
$$


6. Altitude of Burnout

$$
S_{b}=V_{A v} * \Delta t=175.62 * 0.8=140.496 f t
$$

7. Coasting Distance

$$
S_{c}=\frac{V_{b}^{2}}{2(g)}=\frac{351.24^{2}}{2(32.2)}=1915 \mathrm{ft}
$$

8. Total Altitude with no Air Drag

$$
S_{t}=S_{b}+S_{c}=140.496+1915=2055.5 f t
$$

9. Actual Apogee

a. $S_{a}=S_{t} * d=2055.5 * 0.47=966.11$ feet

10. Apogee from Triangulation Calculations

a. $\theta_{\text {Average }}=\frac{\theta_{1}+\theta_{2}+\theta_{3}}{3}=\frac{70^{\circ}+65^{\circ}+69^{\circ}}{3}=68^{\circ}$

b. $S_{\text {Trig }}=$ distance $* \tan \theta_{A v}$

c. $S_{\text {Trig }}=200 f t * \tan 68^{\circ}+3=498 f t$

Conclusion: The model brochure states a value of 732.4 feet for apogee. The simulation results in a maximum apogee of 763.74 feet. In this case, the launch area was not long enough to get better angular measurements. Ideally, the observer would have be 300 feet or more away so that angle observed is not at or near the limit (70) of device. Time to ascend to apogee was observed as 5.5 seconds. 4.8 seconds is due to thrust duration (0.8) and ejection delay (4). There were 16 other team launches using this more powerful engine 6-4. Results, however, were less precise with this engine.

This team had the following comment:

"Throughout this project, we learned to work as a team to conduct an engineering experiment. Engineering is a field that is heavily dependent on teams, not individuals. We were able to divide up the work and to work together to complete this analysis and experiment. We also learned about rockets throughout, and how to calculate the height of apogee in multiple different ways. This project was very informative and helpful to all members of the team" 


\section{Educational Impact:}

There were several educational goals expected of this project: 1) develop team work skills, 2) gain appreciation for future coursework in physics, statics, dynamics, and thermodynamics, 3) get an early understanding on the role of experimental (physical and simulated) and analytical approaches to solve engineering problems, 4) gain practice in writing technical team reports, 5) experience a "real life" like hands-on engineering project from start to finish, 6) learn about rockets in general, 7) become excited about engineering and space exploration and be less likely to drop out of engineering or college in general.

These educational goals above were either accomplished or it is too soon to tell as in the case of goal 7 that seeks to improve retention. Team reports show that goals 1, 3, 4, and 5 were accomplished at various levels that ranged from fair to excellent. Teams were required to meet with the instructor and/or the graduate assistant to go over draft versions. Anonymous exit survey taken on the last day of classes indicates that a majority (72\%) of the students felt this project was a very good learning experience for all goals above. Project and coursework related portions of the student course evaluations received average rating of 4.32 out 5 possible points.

In addition, substantial anecdotal evidence suggests that this project had a positive impact on student learning and retention. Positive student comments about the project were not just limited to student exit survey and course evaluations. The instructor kept receiving positive feedback from those who somehow heard about this project. Some of the 96 students enrolled in spring 2015 lab sections chose to enroll selectively so that they can participate in the same project which is being repeated this time with a much larger model rocket. The majority of the students seemed pleased and excited that the overall exercise was conducted with much experimentation instead of traditional lecture only format. Every attempt was made to physically demonstrate the concepts involved in model and, in some cases, real rocket science.

This project was used to teach students using a hands-on and teamwork based approach instead of a traditional lecture. Although the main goal of the project was not to teach model rocketry, students learned it better by doing it hands-on. Majority of the students reacted positively for this approach, but few students thought too much time was spent on project related activities including practice launches. One of the main educational goals, teaching students how and why different methods are used in a team environment to solve an engineering problem, was accomplished.

\section{Conclusions:}

Students, overall, felt that this was a good project because it was much more than just merely launching model rockets as some had done in middle or high school. Students learned many skills they need later in their studies and professional practice. Teamwork is major a skill that they acquired. They organized into a group with specialized responsibilities for the purpose of constructing and launching their rockets and collecting data to be processed and analyzed for writing a report. Students also learned or improved spreadsheet skills while performing data entry and necessary mathematical calculations. Student gained an understanding for how each of the four apogee determination methods works. They realized that results are often inconsistent. 
Other outcomes include gaining a firm belief that engineering data is precious and it must be carefully recorded and saved for future use. All launch results, practice and project, were entered into a spreadsheet and posted on the blackboard. Documentation of lessons learned was an outcome also. Just as in the real practice, model rocket launches are subject to many unexpected and surprising problems including loss of a vehicle with expensive altimeter(s) or other sensors onboard after a successful flight. Each team carefully noted and reported the problem(s) encountered and remedy, if any, to the instructor who entered the information to the master flight log spreadsheet. The main assessment was the weekly group progress reports and the final team reports on the construction and flight of a rocket. Weekly practice activities used RTF larger rockets that had progressively bigger engines with higher average thrust. A majority of students, even those with prior model rocket experience, found this mathematical and practical rocketry based approach very interesting, worthwhile, and useful. Some students found this activity highly interesting, entertaining, educational, and even inspirational. This project increased the interest and enthusiasm for engineering for some students. It also increased the interest of few who were already determined to work in aerospace area and possibly travel to space.

\section{Recommendations:}

Urban location of the campus made it difficult to find as much open space as desired to conduct better experiments. The maximum distance from the launch pad was only 200 feet in Fall 2014. This was not long enough for good triangulation. Many model rockets were lost. This project would work even better if more open space were available. As a result, a parking lot was reserved and used for project launches in Spring 2015. Drag force could be directly calculated without requiring too much advanced mathematics. This will be tried soon. An altimeter should be used as a gold standard if there is a high probability that it can be recovered. This probability can be increased by simply adding additional weight as payload to cause more powerful engines provide a lower apogee. It is always a good idea to check the accuracy of the altimeter itself first by testing it on top floor of a tall building. It was assumed that $\$ 60$ altimeter would work well.

\section{References:}

1. Boyer, L., Ravindra, K, George, J., and Mitchell, K., "Innovative Rocket Model Project for Sophomore Aerospace Engineering Students”, Paper AC 2007-1922, ASEE Proceedings, 2007.

2. Estes Technical manuals at http://www.esteseducator.com/

3. Stine, H. "The Handbook of Model Rocketry", $6^{\text {th }}$ edition, Wiley

4. www.rocketmine.com

5. Rocksim, Apogee Components, Colorado Springs, CO.

6. www.ck12.org/book/CK-12 


\section{Appendix}

\section{Model Rocketry Safety Code [2]}

Model Rocketry Safety Code of the National Association of Rocketry and the Model Rocket Manufacturers Association is discussed in the lab before any activity starts.

"1. Materials -My model rocket will be made of lightweight materials such as paper, wood, rubber, and plastic suitable for the power used and the performance of my model rocket. I will not use any metal for the nose cone, body, or fins of a model rocket.

2. Engines/Motors -I will use only commercially-made NAR certified model rocket engines in the manner recommended by the manufacturer. I will not alter the model rocket engine, its parts, or its ingredients in any way.

3. Recovery -I will always use a recovery system in my model rocket that will return it safely to the ground so it may be flown again. I will use only flame resistant recovery wadding if required. 4. Weight and Power Limits -My model rocket will weigh no more than 1,500 grams (53 ounces) at liftoff, and its rocket engines will produce no more than 320 Newton-seconds (4.45 N equal 1.0 pound) of total impulse. My model rocket will weigh no more than the engine manufacturer's recommended maximum liftoff weight for the engines use, or I will use engines recommended by the manufacturer for my model rocket.

5. Stability -I will check the stability of my model rocket before its first flight, except when launching a model rocket of already proven stability.

6. Payloads -Except for insects, my model rocket will never carry live animals or a payload that is intended to be flammable, explosive, or harmful.

7. Launch Site -I will launch my model rocket outdoors in a cleared area, free of tall trees, power lines, building and dry brush and grass. My launch site will be a least as large as that recommended in the following table.

8. Launcher -I will launch my model rocket from a stable launch device that provides rigid guidance until the model rocket has reached a speed adequate to ensure a safe flight path. To prevent accidental eye injury, I will always place the launcher so the end of the rod is above eye level or I will cap the end of the rod when approaching it. I will cap or disassemble my launch rod when not in use, and I will never store it in an upright position. My launcher will have a jet deflector device to prevent the engine exhaust from hitting the ground directly. I will always clear the area around my launch device of brown grass, dry weeds, or other easy-to-burn materials.

9. Ignition System -The system I use to launch my model rocket will be remotely controlled and electrically operated. It will contain a launching switch that will return to "off' when released. The system will contain removable safety interlock in series with the launch switch. All persons will remain at least 15 feet (5 meters) from the model rocket when I am igniting model rocket engines totaling 30 newton-seconds of less of total impulse. I will use only electrical igniters recommended by the engine manufacturer that will ignite model rocket engine(s) within one second of actuation of the launching switch. 
10. Launch Safety -I will ensure that people in the launch area are aware of the pending model rocket launch and can see the model rocket's liftoff before I begin my audible five- second countdown. I will not launch a model rocket using it as a weapon. If my model rocket suffers a misfire, I will not allow anyone to approach it or the launcher until I have made certain that the safety interlock has been removed or that the battery has been disconnected from the ignition system. I will wait one minute after a misfire before allowing anyone to approach the launcher.

11. Flying Conditions -I will launch my model rocket only when the wind is less than 20 miles (30 kilometers) an hour. I will not launch my model rocket so it flies into clouds, near aircraft in fight, or in a manner that is hazardous to people or property.

12. Pre-Launch Test -When conducting research activities with unproven model rocket designs or methods I will, when possible, determine the reliability of my model rocket by pre-launch tests. I will conduct the launching of an unproven design in complete isolation from persons not participating in the actual launching.

13. Launching Angle -My launch device will be pointed within 30 degrees of vertical. I will never use model rocket engines to propel any device horizontally.

14. Recovery Hazards -If a model rocket becomes entangled in a power line or other dangerous place, I will not attempt to retrieve it."

The rest of the appendix shows various launch related pictures and simulation results for the two models used in Fall 2014. 


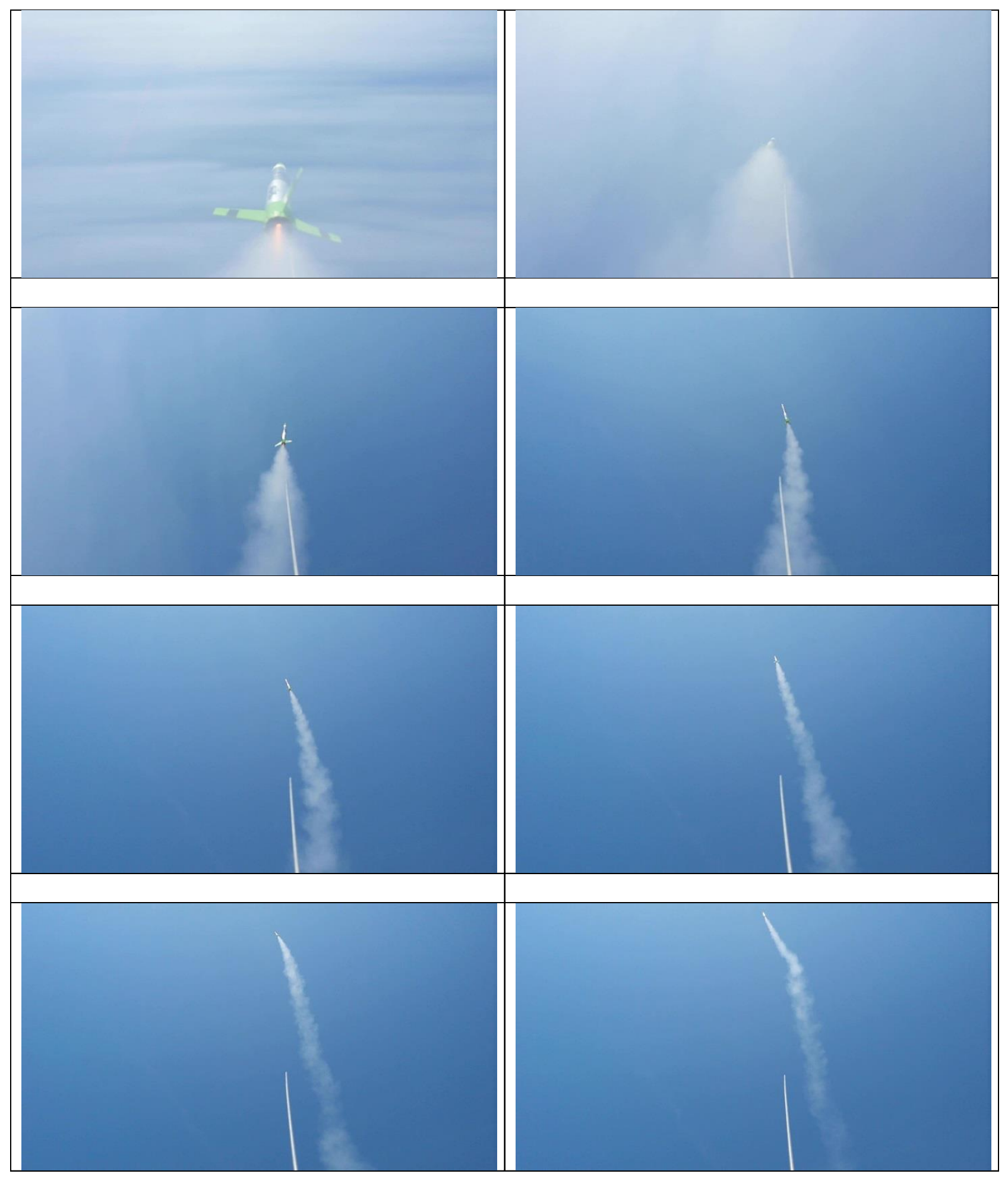

Figure A.1 Skytrax launch pictures taken from the launch pad base. 


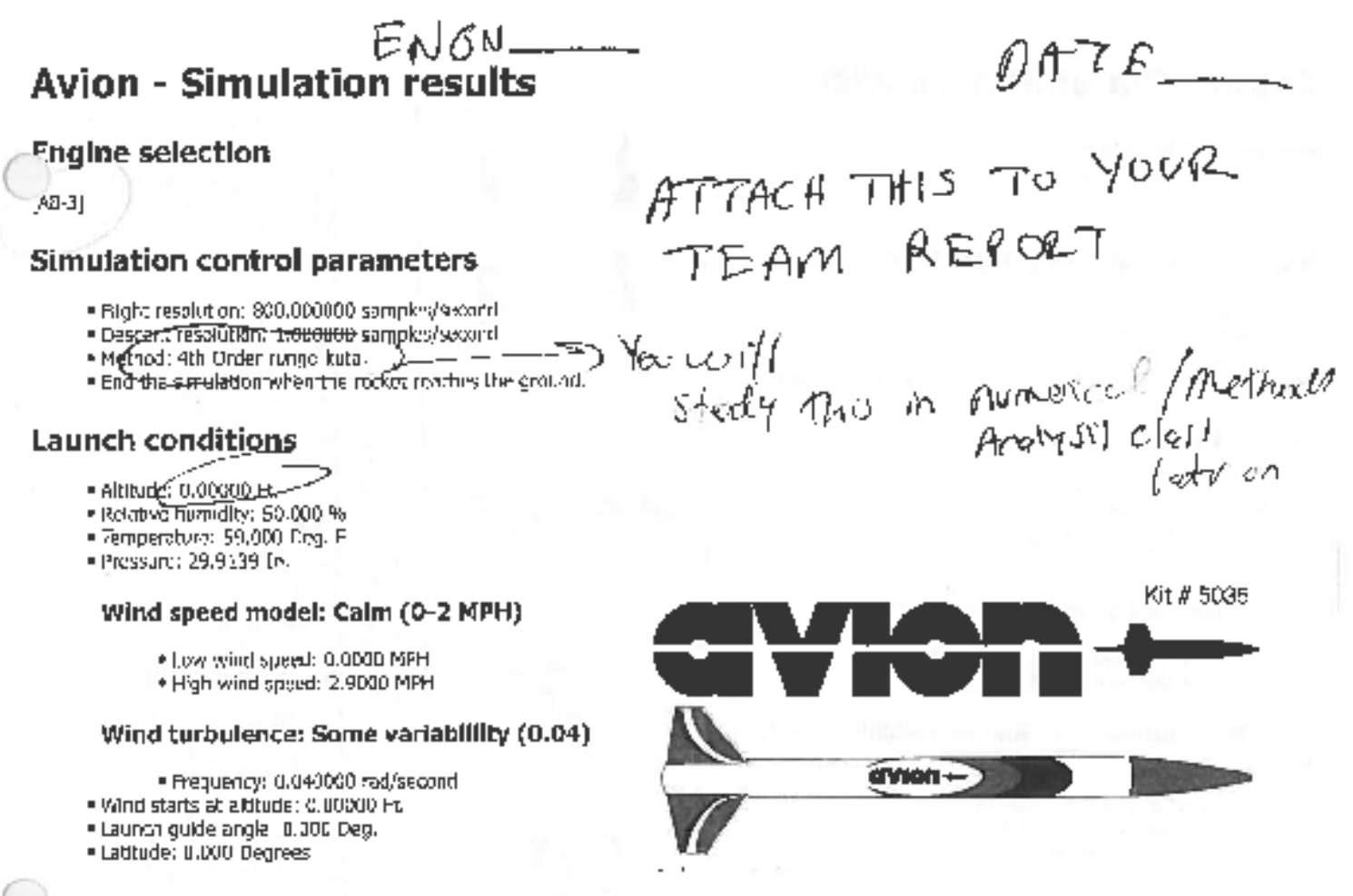

\section{aunch guide datar}

- Laurcti gl de lengut 16. Uitol dn

- velaciri z: laurci gulje departure: 5E.5581 fís

- The Ieurci gulde was cleared it: : 0.214 Seconds

- Liser specrles min!rium veoctty far stale fl ght: 43.9993 nís

- Minimurn velocito lor stable tilght rexehed at: 26,1566 [n.

\section{Max data values:}

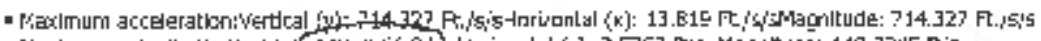

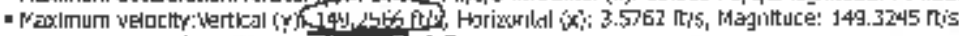

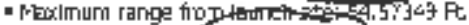

- Plaxinum alutude (300.74ba3 It.

Avion brochure

Englne ejectlon charge data:

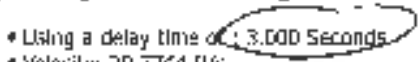

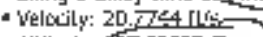

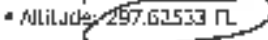

\section{Recovery system data}

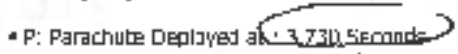

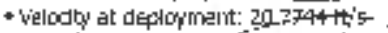

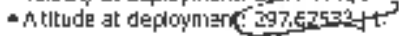

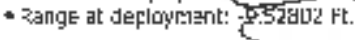

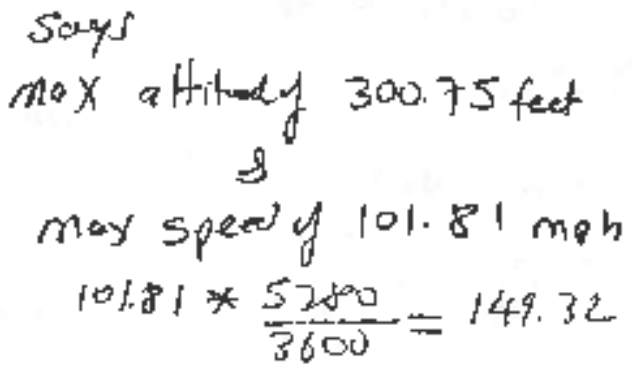

'ime data

- Time to bulmout $1.731 \mathrm{sec}$.

- Tme bo ajoger: $4.125 \mathrm{sec}$.

- Jptimal electan delay; 3.3y4 box.

\section{Landing data}




\section{Avion - Simulation results}

\section{Engine selection}

$[30 \div-1]$

\section{Simulation control parameters}

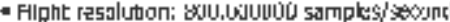
- Desseri resdutisn: i, 600000 sampley/oroand

- Metcodi ath ordar runje cuto.

- Exd the smulabor when the rodat rejecties the giound.

\section{Launch conditions}

- Altroude: 0,00000 F-

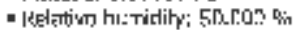

- Icmp:ralume 59.060 [joy. F

- Pesgire; 79.9] 79 [n.

Wind speed model: Calm (0-2 MPH)

- Low wird heed: 0.00Ja MFH

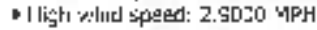

Wind turbukenc: Some varlab]llity (0.04)

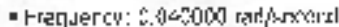

- Vilnd storts at alutudc: D.,000 FI.

- Launeh pulds anglc: 0.090 0og.

- Latroude: 0.000 [xogress

\section{Launch guide data:}
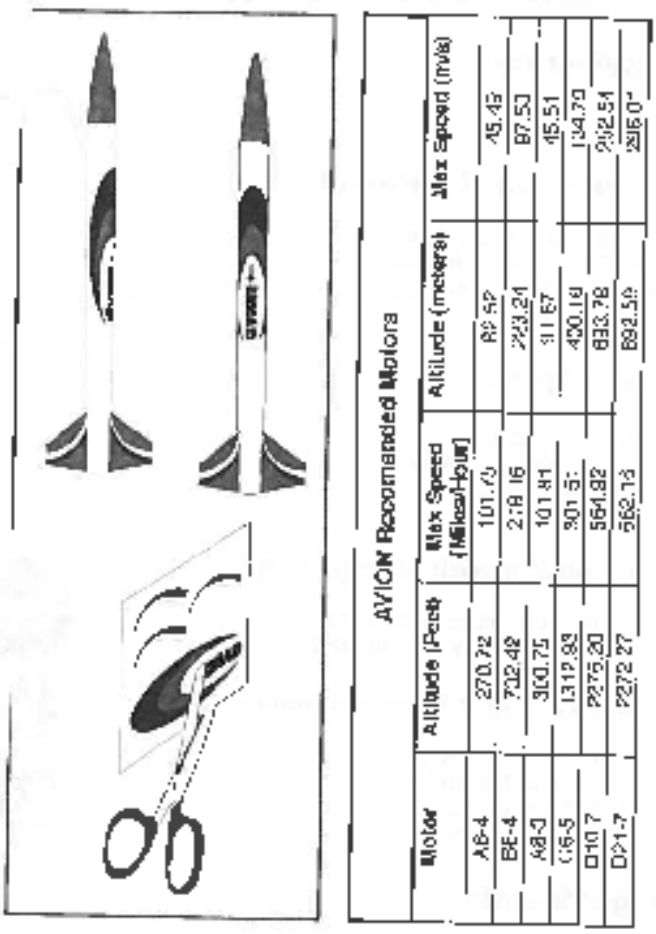

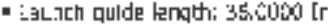

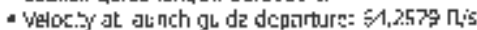

- The launch qude twas cleared at ; 0.15n Sirririrs

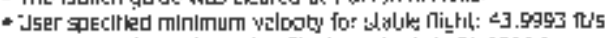

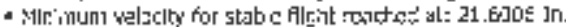

\section{Max data values;}

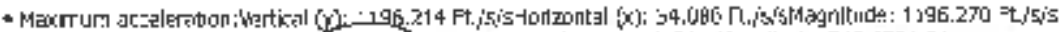

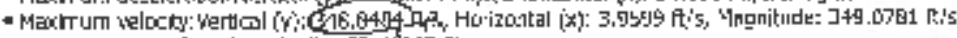

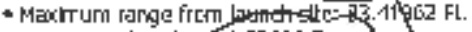

- Maxtrum altituda- $603.75898 \mathrm{Ft}$ Aur on

Engine ejection charge data:

- L.silty a delay tire af : 4.300 serands

- vek:cilly: -3.6701 itis

- Sltituce: 75․ 28790 =t.

\section{Recovery system data}

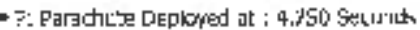
- vialary at doplopment: 43.9701 fú: - Antude zt deploymert: 738.2674 ) $\mathrm{F}$

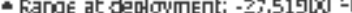

\section{Time data}

$\rightarrow$ brochure soys 732.42 feet

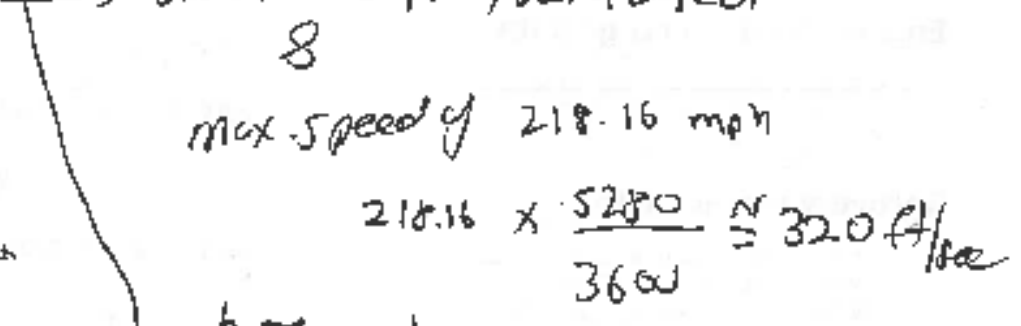

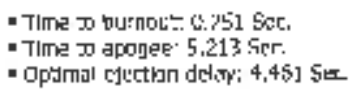

Landing data

- Fange at landing \$3.<1962

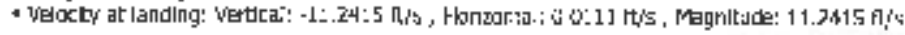




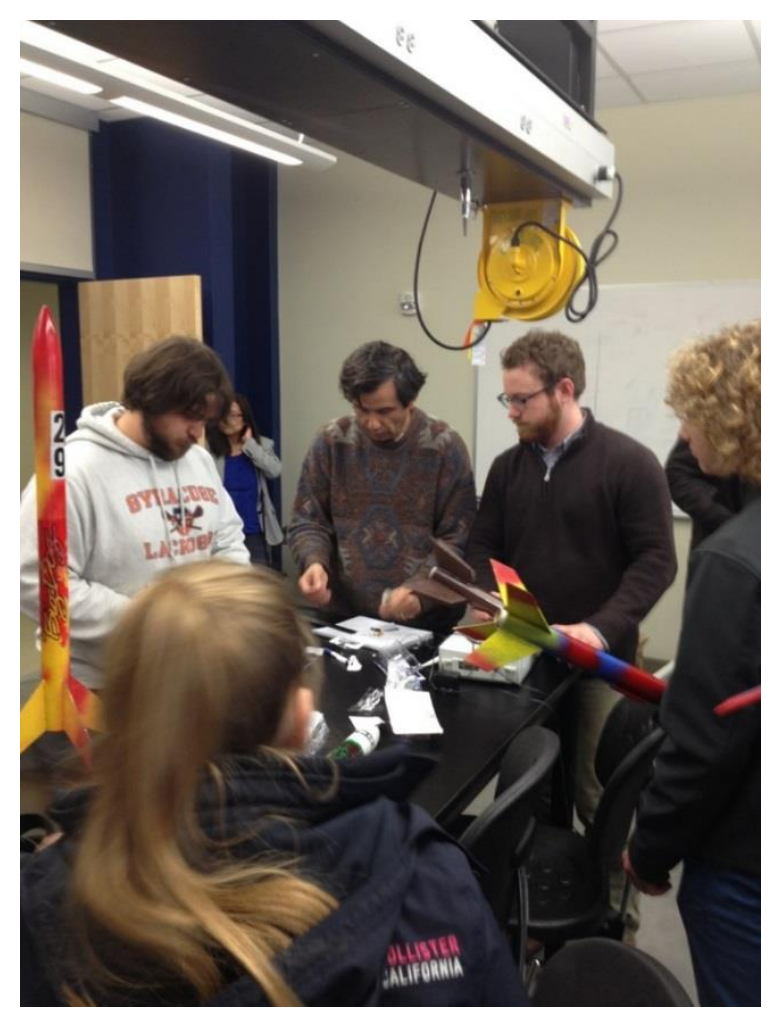

Figure A.2. E16-6 Engines being installed in Big Dog CFK model rockets (Spring 2015)

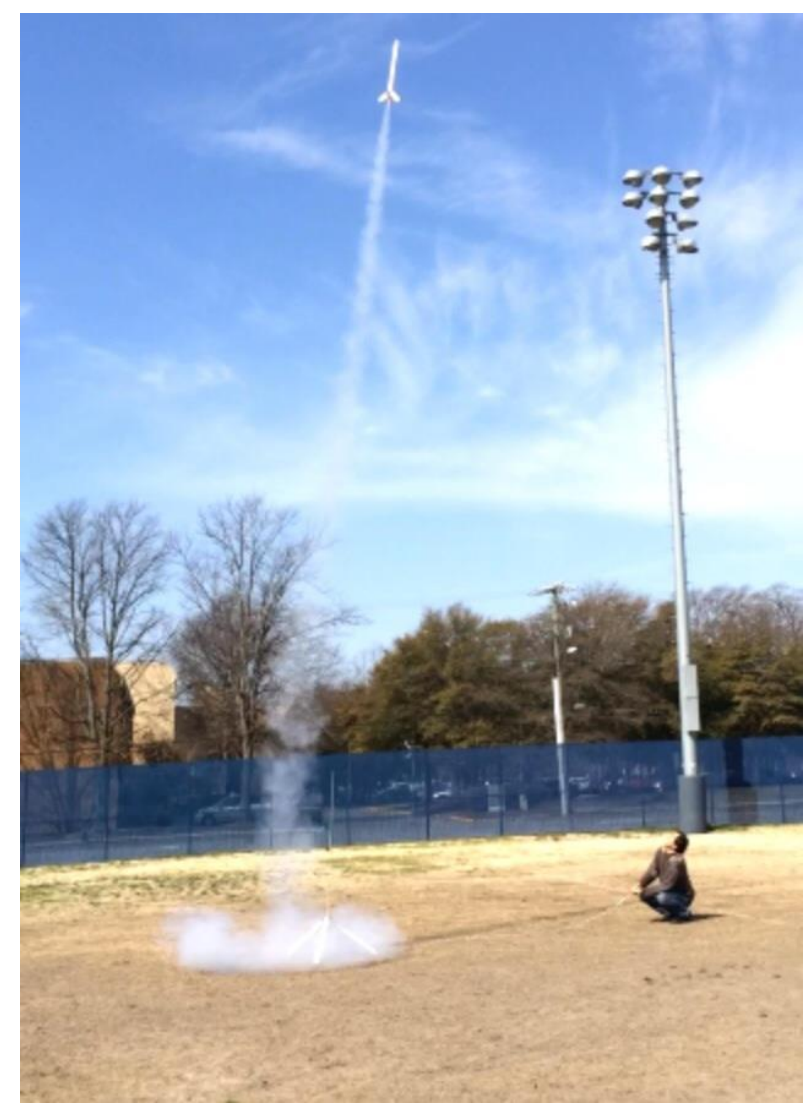

Figure A.3. Big Dog CFK model rocket flown on a D12-5 Engine (Spring 2015)

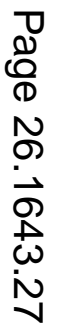




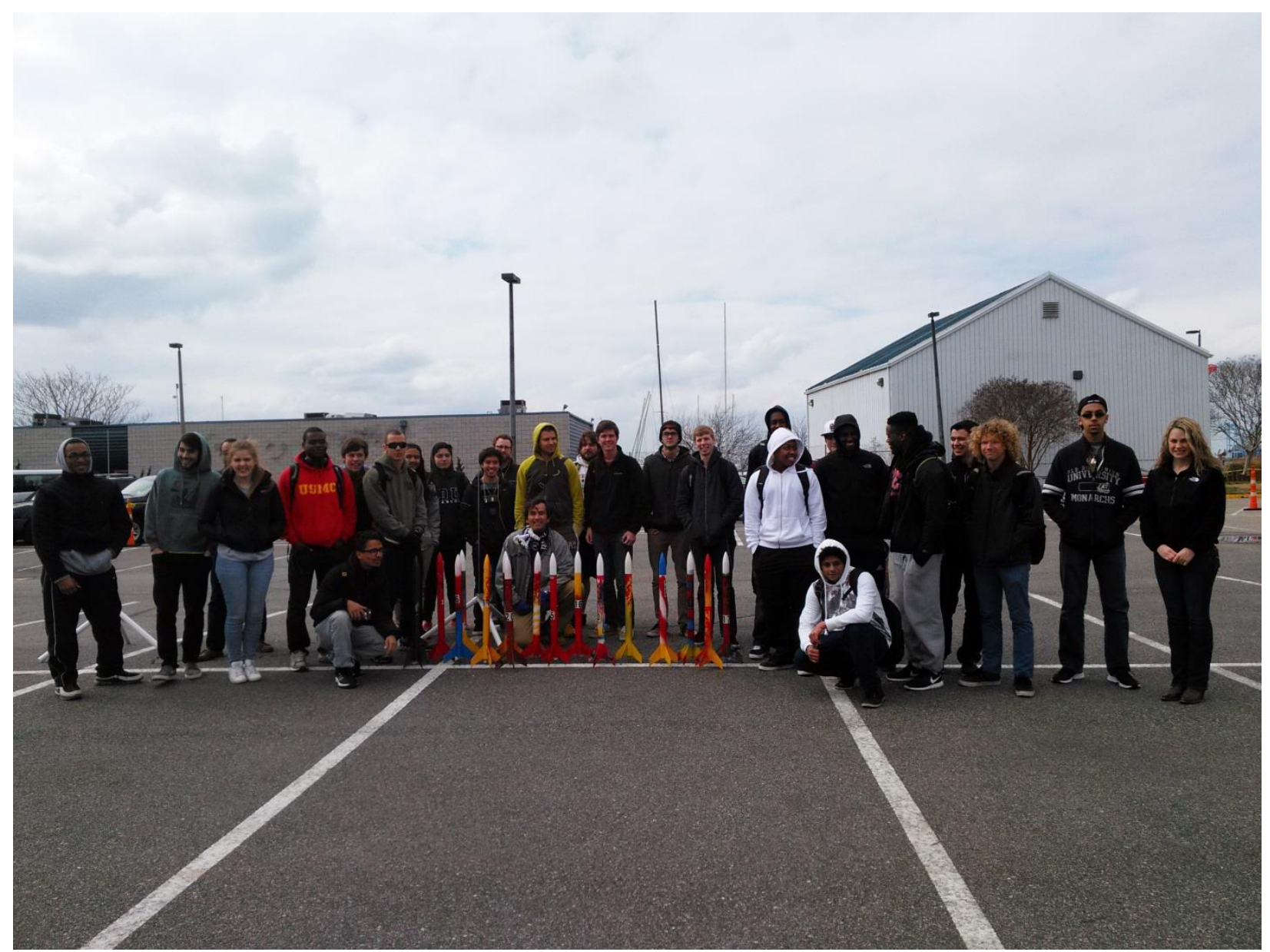

Figure A-4. Big Dog CFK model rocket demonstration event on 3/28/2015

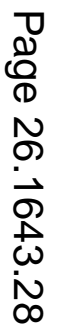




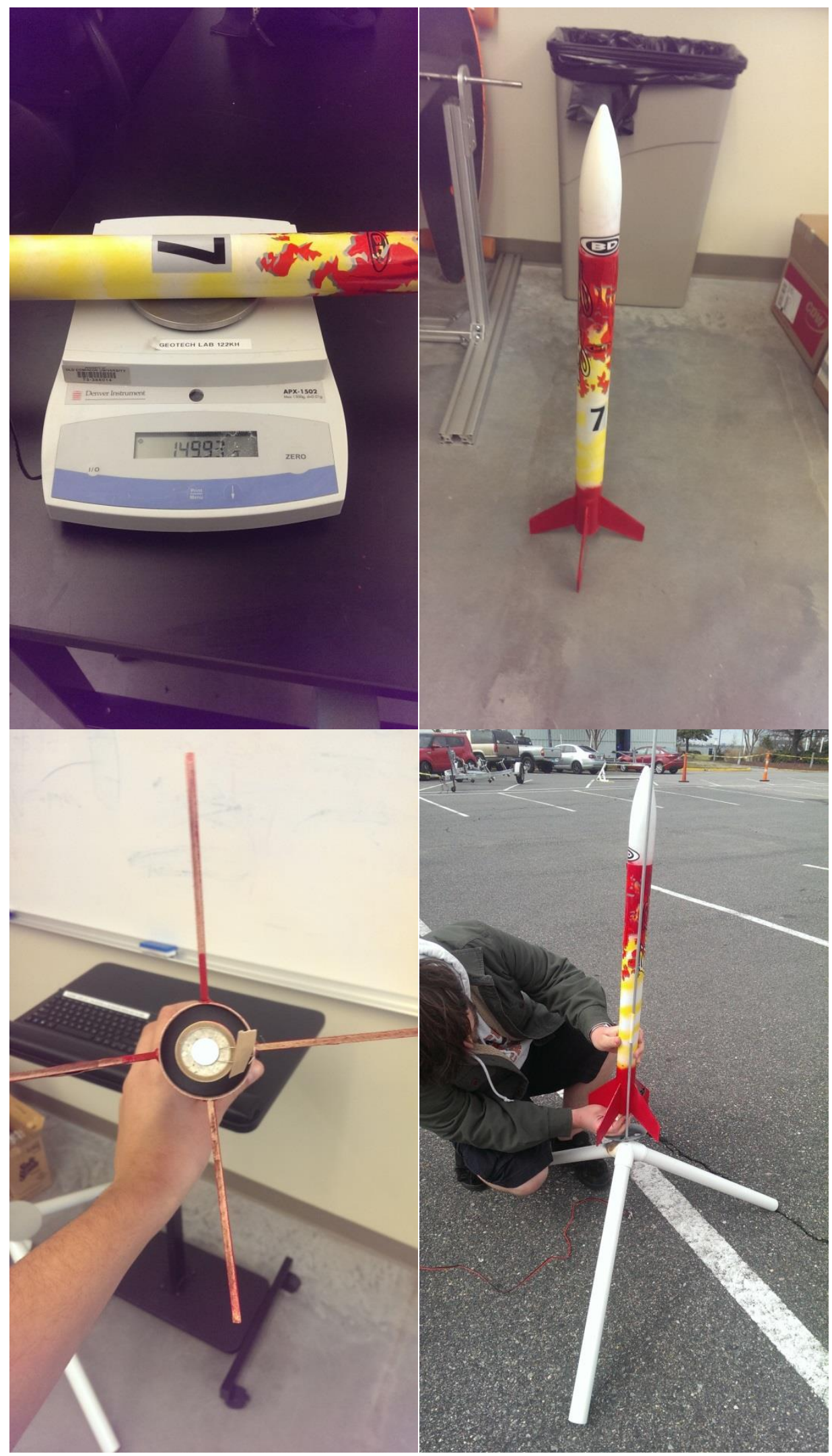

Figure A-5. Various launch preparation activities (Spring 2015)

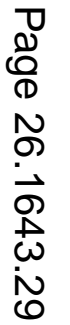




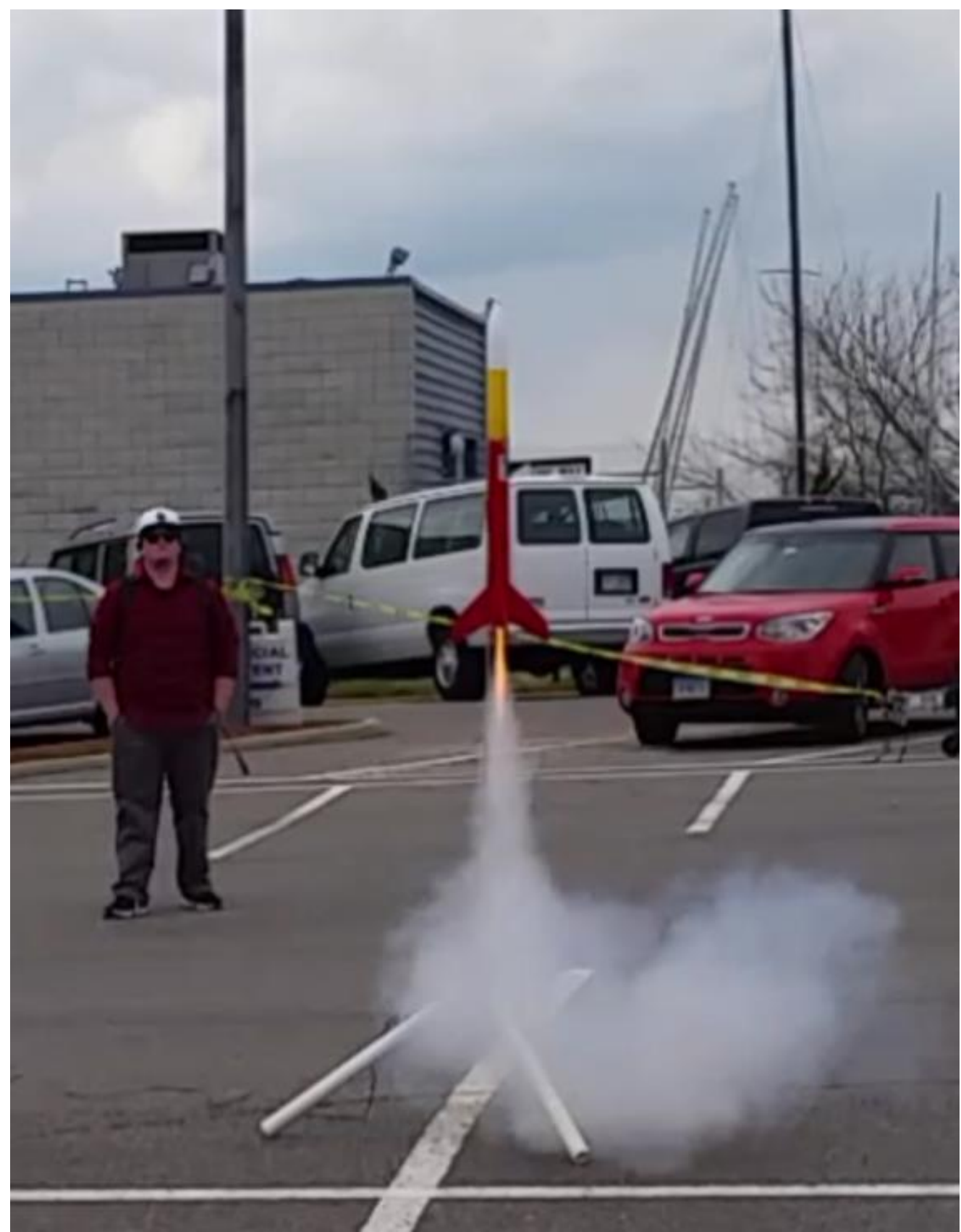

Figure A-6. Big Dog CFK model rocket clears the launch pad

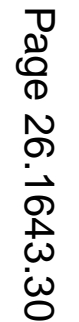




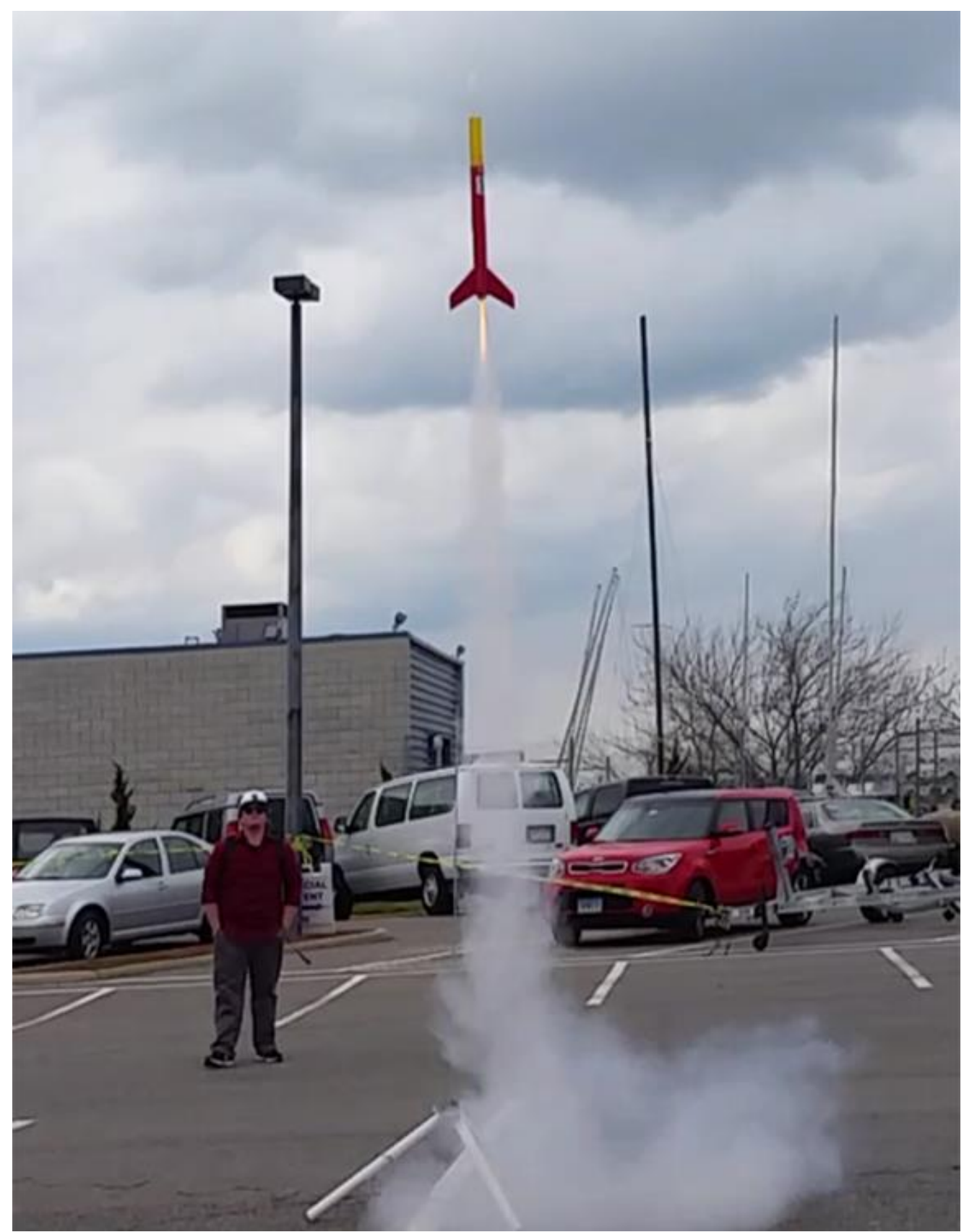

Figure A-7. Big Dog CFK model rocket accelerates toward to the burnout point

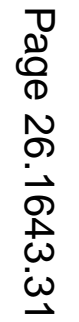

